\title{
La producción dramática inédita de Francisco Galeas (Hispanic Society of America, Ms. HC380/611) Francisco Galeas's Unpublished Dramatic Works (Hispanic Society of America, Ms. HC380/611)
}

\section{Mercedes de los Reyes Peña}

Universidad de Sevilla

ESPAÑA

mdelosreyesp@telefonica.net

[Hipogrifo, (issn: 2328-1308), 5.1, 2017, pp. 115-154]

Recibido: 28-04-2016 / Aceptado: 30-05-2016

DOI: http://dx.doi.org/10.13035/H.2017.05.01.10

Resumen. Como indico al principio del artículo, en él se da a conocer la reducida producción dramática inédita de un escritor del último tercio del siglo XVI y principios del siglo XVII. Además de incorporarla a la historia del teatro, pongo de manifiesto cómo un dramaturgo amateur, perteneciente a una época en la que el teatro se estaba profesionalizando a pasos agigantados, es responsable de la puesta en escena de su obra y cómo las circunstancias personales y externas influyeron en su creación. De aquí, la necesidad de situarlo en la diacronía de su propia historia biográfica y literaria.

Palabras clave. Francisco Sánchez Galeas, Francisco Galeas, datos biográficos, Cartuja de las Cuevas (Sevilla), producción dramática, teatro religioso, último tercio del Quinientos-principios del Seiscientos.

Abstract. As indicated at the beginning of this paper, it deals with a small number of unpublished plays by a late 16th - early 17 th century writer. Apart from incorporating his production to the history of drama, I try to lay emphasis on the fact that he, being an amateur playwright, was responsible for the performance of his own plays, at an age when theatre was rapidly becoming commercial and professional. The way his personal circumstances influenced his own creative work is also taken 
into account. This author has certainly to be viewed within his own time and personal and literary history.

Keywords. Francisco Sánchez Galeas, Francisco Galeas, Biographical Data, Las Cuevas Charterhouse, Seville, Dramatic Works, Religious Drama, Late 16thEarly 17 th Centuries.

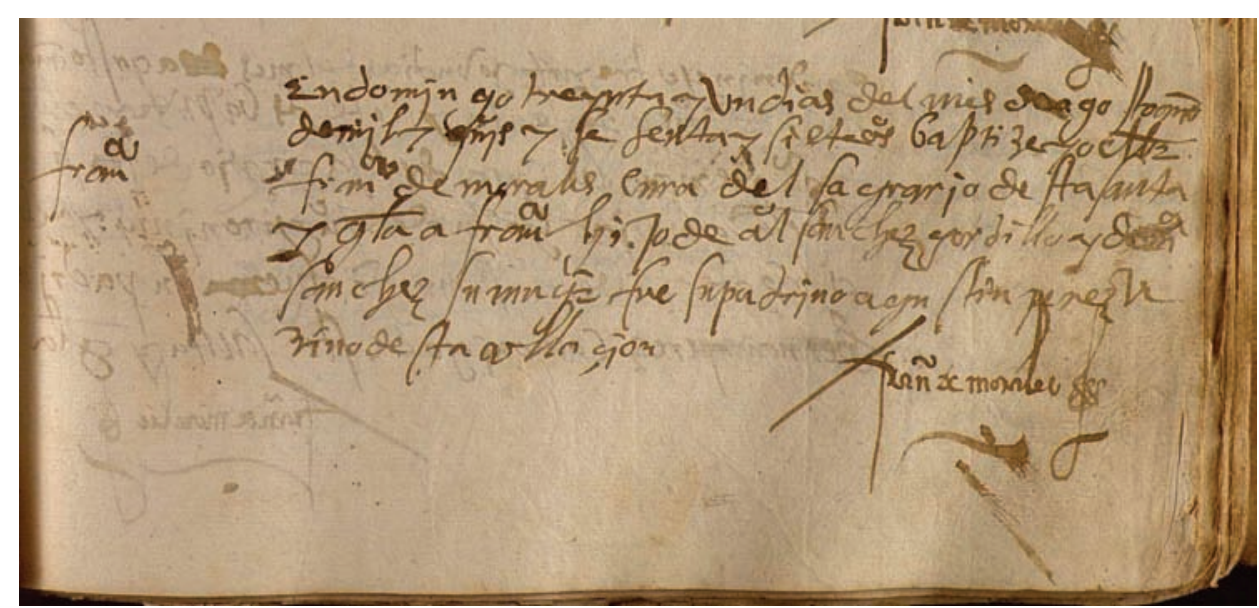

Imagen I.

En homenaje al Prof. D. Francisco Ruiz Ramón, que tanto amó el teatro y que tanto nos enseñó en la forma de acercamiento a su investigación y estudio, daré a conocer la reducida producción dramática inédita de un escritor del último tercio del siglo XVI y principios del siglo XVII. Además de incorporarla a la historia del teatro, pondré de manifiesto cómo un dramaturgo amateur, perteneciente a una época en la que el teatro se estaba profesionalizando a pasos agigantados, es responsable de la puesta en escena de su obra y cómo las circunstancias personales y externas influyeron en su creación. De aquí, la necesidad de situarlo en la diacronía de su propia historia biográfica y literaria.

Se trata de Francisco Galeas o Francisco Sánchez Galeas, un monje perteneciente al monasterio cartujo de Santa María de las Cuevas de Sevilla, situado extramuros de la ciudad, a orillas del Guadalquivir, que con sus inundaciones lo maltrataba con cierta frecuencia. Nacido en el año 1567, recibió las aguas bautismales, el día 31 de agosto, en la Parroquia del Sagrario (Catedral), como atestigua su partida de bautismo. Inédita, arroja luz definitiva sobre su fecha de nacimiento y ratifica la identidad de sus progenitores. He aquí transcrito su breve texto:

En domingo, 31 días del mes de agosto año de mil y quinientos y sesenta y siete años, bapticé yo, el bachiller Francisco de Morales, cura del Sagrario desta Santa Iglesia, a Francisco, hijo de Alonso Sánchez Gordillo y de María Sánchez, su mujer. Fue su padrino Agustín Pérez, vecino desta collación. 
Francisco de Morales [firma y rubrica]'.

Una identidad que queda de nuevo ratificada en la «probanza ad perpetum» demandada y emitida el 14 de septiembre de 1590, ante el licenciado Lope Ortiz de Valderrama, teniente de asistente de Sevilla, en presencia de Joan Pérez Galindo, ecribano público. La petición fue presentada por fray Alonso de Ojeda, profeso y procurador del monasterio de Santa María de las Cuevas, en nonbre del prior, monjes y convento, con objeto de probar la legitimidad genealógica, familiar y ciudadana de Francisco Sánchez Galeas², entonces novicio, necesaria antes de su profesión ${ }^{3}$. Los cuatro testigos aportados por fray Alonso de Ojeda debían responder a las siguientes preguntas:

Primeramente, si conosen a Alonso Sánchez Gordillo y a María Sanches, su mujer, y a Francisco Sanches Galeas, su hijo, vecinos desta ciudad.

Iten, si saben que el dicho Alonso Sánchez Gordillo fue casado según orden de la Santa Madre Iglesia con la dicha María Sanches, su mujer, y durante entre ellos el matrimonio hubieron y procrearon por su hijo ligitimo y natural a el dicho Francisco Sánchez Galeas, su hijo, y por tal su hijo lo nombraron y trataron, y fue y es habido y tenido y comúnmente reputado.

Iten, si saben que todo lo susodicho es pública voz y fama 4 .

De sus sucesivas declaraciones, se desprenden datos curiosos sobre lo que pudo ser la infancia y adolescencia de nuestro escritor. Recordemos que en este momento, cuando los testigos vuelven atrás sus respectivas miradas para responder bajo juramento a las preguntas formuladas, Francisco Sánchez Galeas tenía 23 años y era novicio de la Cartuja de las Cuevas. Por sus respuestas, sabemos que sus padres, ya difuntos, habían vivído en la calle de Escobas y que los declarantes los conocían de más de veintiocho, veinticinco, veintisiete y treinta años, respectivamente; y que conocían a Francisco Galeas, tres de ellos desde su nacimiento y el cuarto «desde el tiempo que andaba a la escuela». Todos afirman que los pa-

1. Institución Colombina, Archivo de la Parroquia del Sagrario de Sevilla, Libro de Bautismos, 8, 1566-1569, fol. 98r. Agradezco a la Sra. Directora de la Institución Colombina el permiso de reproducción de la partida de bautismo, así como la amabilidad de sus facultativos durante la consulta de los fondos. Dado el criterio editorial seguido por la revista, modernizamos las transcripciones de los documentos, respetando las características propias de la época en los tres niveles del signo lingüístico y manteniendo las contracciones frecuentes del momenro: deste, dese, dellos... Agradezco, igualmente, a D. Vicente Palacios (ALQUIVIRA. Diseño y Producción S. L.), la preparación de las imágenes del artículo para su reproducción.

2. Archivo Histórico Provincial de Sevilla, Sección de Protocolos Notariañes, Oficio IV, Joan Pérez Galindo, leg. 2396, fols. 801 r-804r.

3. En Svmaria relación del insigne Monasterio de Santa María de las Cuevas de Sevilla..., ordenada por el Licenciado Alonso Sánchez Gordillo (hermano de nuestro autor, como veremos más adelante), en 1663, a la edad de 72 años, se lee que, tras el año de noviciado, si el Convento aprueba admitir al novicio como profeso «prepárase nuevo hábito, sotana blanca y cogulla con escapulario trabado de ambos lados y hace el Convento sus informaciones de calidad y otras cosas que ha de uso» (2003, p. 369), debiendo colocar en este contexo esa «probanza ad perpetum» a la que hacemos referencia.

4. Archivo Histórico Provincial de Sevilla, Sección de Protocolos Notariales, Oficio IV, Joan Pérez Galindo, leg. 2396, fol. $801 r-v$. 
dres estaban casados y velados por la Santa Madre Iglesia; que vivían en una casa y compañía en la calle de Escobas y que llevaban vida «maridable», procreando a Francisco por su hijo legítimo y natural, a quien criaron, alimentaron, trataron y nombraron hijo y él a ellos padres; y que en tal reputación fueron habidos y tenidos. La edad de los testigos (sesenta, cincuenta y ocho, cuarenta y seis años, más o menos, los tres que la confiesan) puede ser reflejo de la edad que hubieran podido tener los padres de Galeas; y su condición, mercaderes -tres de ellos lenceros-, del ambiente en que crecería el escritor.

Conviene recordar que la calle de Escobas, actual Álvarez Quintero en la parte más cercana a la Catedral, donde Galeas nació y vivió, era una bulliciosa calle de mercaderes y artesanos, jalonada por tiendas (un total de 62 en 1679), cuyos dueños exponían sus artículos en los portales. «De la variedad de nombres de oficios con que se ha conocido su primera mitad [la más cercana a la Plaza del Salvador] -leemos en el Diccionario histórico de las calles de Sevilla-, se deduce la importancia de la actividad económica que desarrolló desde los siglos medievales, relacionada con la fabricación de ropa y complementos, fundamentalmente cordoneros, ropavejeros y roperos, lenceros, joyeros, talabarteros, guarnicioneros, polaineros, chapineros» ${ }^{5}$. A comienzos del siglo XVII, seguimos leyendo en el citado Diccionario, existía también una escuela, cuyo maestro pedía autorización en 1623 para sacar los bancos a la acera $^{6}$. No sabemos si sería ésta donde Galeas cursó sus primeras letras.

La buena situación de la calle, en el centro de la ciudad entre la Plaza del Salvador y la Catedral, su gran actividad comercial, las profesiones de los declarantes que testifican en el documento arriba citado y las mandas del testamento de Galeas, como ahora veremos, lo muestran como perteneciente a una familia de la burguesía media sevillana.

Antes de profesar, estando en el término de los dos meses últimos del año del noviciado, «fray Francisco Galeas, monje novicio del monesterio y convento de Nuestra Señora de Santa María de las Cuevas de la orden de Cartuja», otorga carta de testamento ante escribano público en el Monasterio de la Cartuja, el 1 de octubre de 15907. Lo hace autorizado por una licencia, emitida el 17 de septiembre de 1590 por el licenciado Bernardino Rodríguez (provisor general de esta ciudad de Sevilla), para poder testar conforme al santo concilio tridentino y renunciar a la legítima de sus padres en la persona y personas que quisiere y por bien tuviere, que se adjunta.

Pimeramente, Galeas encomienda su cuerpo y su alma a Dios para servirle los días que le diere de vida en la orden y convento de la Cartuja y acuerda cincuenta misas en acción de gracias por haberle traído el Señor a dicha orden para la salvación de su alma. Atendida la cuestión espiritual, se centra en las mandas relativas a sus posesiones materiales. Por ellas, conocemos que el joven novicio gozaba de

\footnotetext{
5. Diccionario histórico de las callles de Sevilla, 1993, s. v. «Álvarez Quintero, calle», t. I, pp. $79-80$ (la cita en p. 80) 6. Diccionario histórico de las calles de Sevilla, 1993, s. v. «Álvarez Quintero, calle», t. I, p. 80.

7. Archivo Histórico Provincial de Sevilla, Sección de Protocolos Notariañes, Oficio IV, Joan Pérez Galindo, leg. 2396, fols. 782v-784v (la cita literal en fol. 782v). De este documento, da noticias Carmen Álvarez Márquez, 2000, pp. 110 y 234: 2013, pp. 183-184; y 2014, p. 93.
} 
una situación económica bastante desahogada que lega a su hermano el licenciado Alonso Sánchez Gordillo, con ciertas condiciones que se van precisando, como era habitual en este tipo de negocio jurídico, y en las que no nos detendremos:

a) Disfrutaba del alquiler de unas casas de por vida en la Especería de la ciudad, cuya propiedad era de doña Luisa Fajardo, que Galeas, a su vez, tenía alquiladas.

b) Poseía con su hermano Alonso Sánchez Gordillo «una heredad de viñas y olivar con un pinal [sic] con casa y bodega y las demás cosas que le pertenesce, que es en término de Alcalá de Guadaira, la cual heredamos de Ana Gómez, nuestra hermana difunta, en común por mitad por iguales partes sin división alguna» ${ }^{8}$. Heredad, cuya parte lega a Diego García, su cuñado y albacea del testamento (junto a Alonso Sánchez Gordillo), y a su mujer, su prima María Vázquez, con la obligación de que, si su hermano para saldar las deudas pendientes con el dicho Diego García decidiera vender su parte, su cuñado se obligaría a comprarla, aunque su precio fuera menor que el de la deuda, porque lo que faltare quedaría cubierto con la donación; $y$, en el caso de que su hermano no quisiese vender su mitad, Diego García y su mujer disfrutarían de la que Galeas les había donado tal como él la poseía?.

c) Por último, hace depositario a su hermano Alonso Sánchez Gordillo del encargo de pagar de sus bienes la cantidad de 200 ducados que su hermana Ana Gómez y su marido dejaron en su testamento a un niño, Gabriel de la Magdalena, que habían criado, y 50 ducados que su hermana había dejado a Juana Rodríguez, prima de Galeas, para su casamiento, los cuales se le habrían de dar cuando tomare estado. A cuenta de estos 250 ducados, conocemos que el novicio también dejaba dos pares de casas en Triana, en la calle del Argamazón, que legaba a su hermano, pero, no fiándose al parecer demasiado de él, ordenaba que, si las casas se vendieran antes de que se pagaran los 250 ducados, éstos se sacaran del precio de ellas y se entregaran a su cuñado Diego García para que los administrara y llevara a efecto lo mandado ${ }^{10}$.

Una vez cumplidas las cláusulas de este testamento, deja por heredero universal de todo lo que le quedare hasta el tiempo de su profesión a su hermano el licenciado Alonso Sánchez Gordillo, con la excepción de que

dicho mi hermano y heredero no haya ni tenga derecho alguno a los libros e otras qualesquier cosas que yo haya traído al dicho monesterio e se trujeren hasta el día de mi profesión, porque los dichos libros e las demás cosas juntamente con mi persona he de entregar y entrego dende el dicho día en adelante al dicho monesterio y a Prelado dél ${ }^{11}$.

8. Archivo Histórico Provincial de Sevilla, Sección de Protocolos Notariañes, Oficio IV, Joan Pérez Galindo, leg. 2396, fol. $783 \mathrm{v}$

9. Archivo Histórico Provincial de Sevilla, Sección de Protocolos Notariañes, Oficio IV, Joan Pérez Galindo, leg. 2396, fol. 783v.

10.Archivo Histórico Provincial de Sevilla, Sección de Protocolos Notariañes, Oficio IV, Joan Pérez Galindo, leg. 2396, fols. 783v-784r.

11. Archivo Histórico Provincial de Sevilla, Sección de Protocolos Notariañes, Oficio IV, Joan Pérez Galindo, leg. 2396, fol. 784v. Éste es el único pasaje de su testamento que ha sido publicado: Álvarez Márquez, 2000, p. 110; 2013, p. 183; y 2014, p. 93. 
Desconocemos cuáles serían esos libros que aportó a la biblioteca del monasterio, de los que se seguiría sirviendo - suponemos-, junto a sus fondos, durante la vida conventual, pero, gracias a la conservación de un ejemplar en la Biblioteca General de la Universidad de Sevilla de los Canones et decreta Sacrosancti oecumenici et generalis Concilii Tridentini sub Paulo III, Julio III, Pio IIII Pontificibus Max., impreso en Alcalá de Henares, por Andrés Angulo, en 1564 (A Res. 14/4/09), con la nota de propiedad de Francisco Sánchez Galeas en la portada ${ }^{12}$, sabemos que éste, al menos, le perteneció (Imagen II).

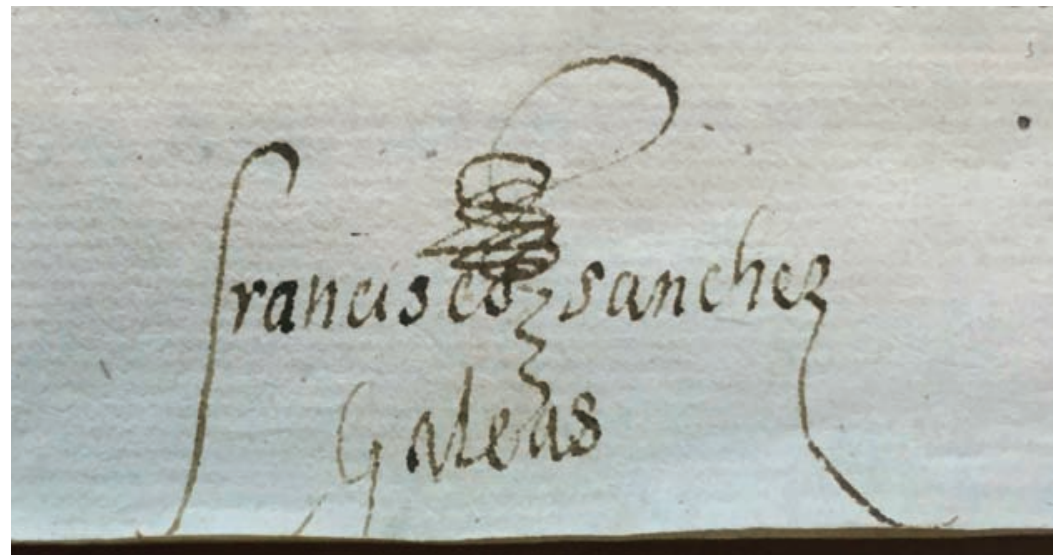

Imagen II.

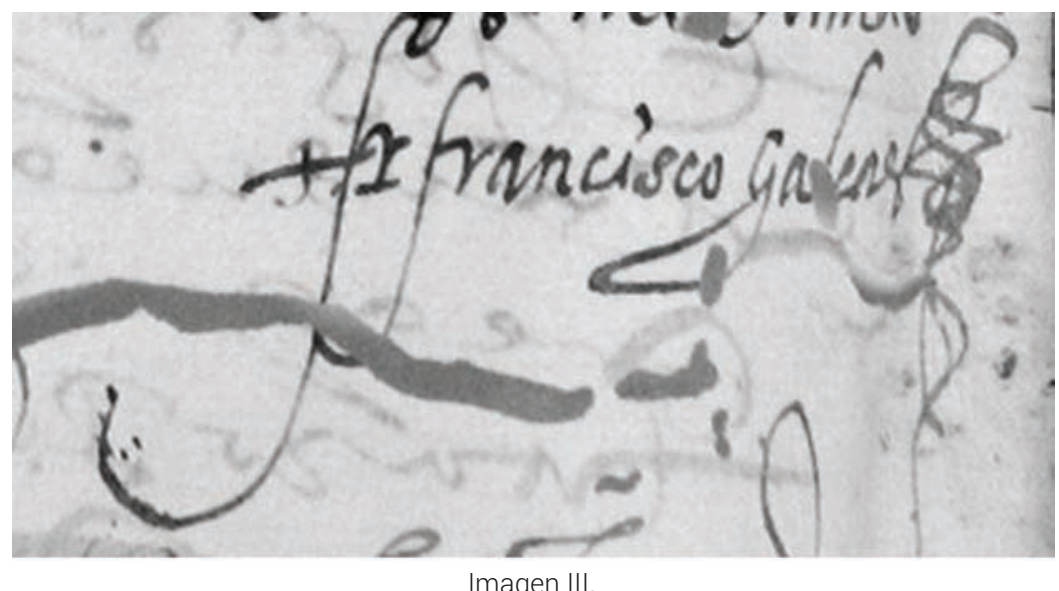

Su firma y rúbrica, estampadas al pie de su testamento (Imagen III), cierran la información que los documentos notariales hasta ahora conocidos suministran sobre él. Esta firma y la anterior, signos de su verdadera identidad, se complementan iconográficamente con dos retratos que lo legan a la posteridad, reflejo eviden- 


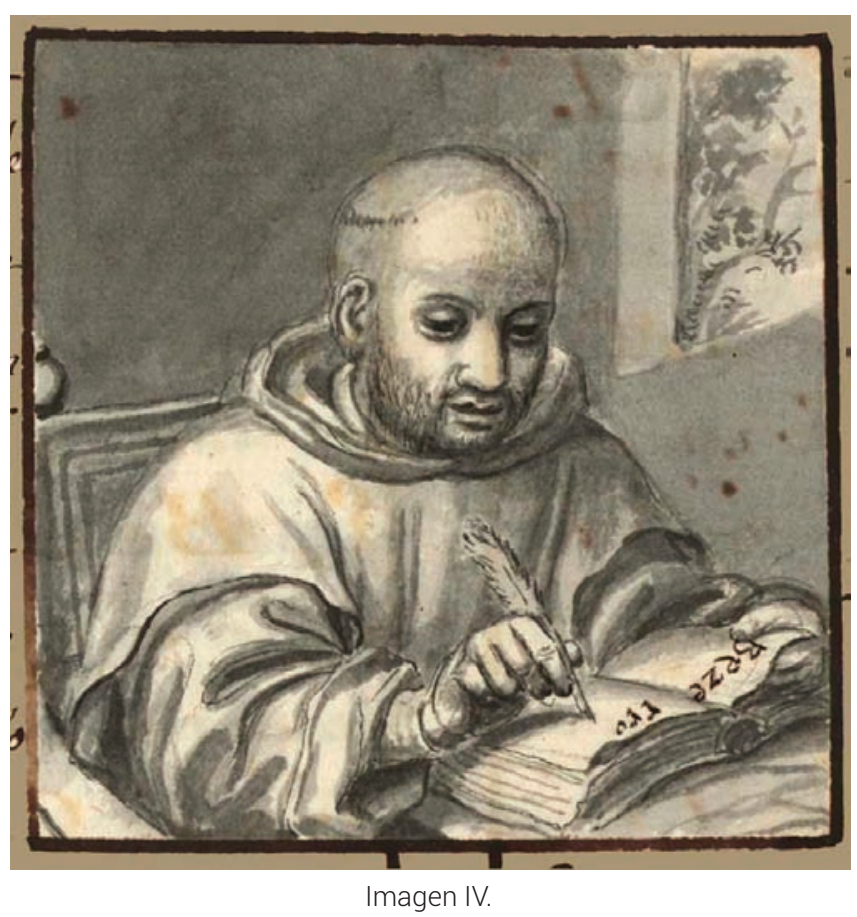

te de la relevancia que gozó en su tiempo. Aparece en ambos en hábito de fraile cartujo con la pluma en la mano y un manuscrito delante. Uno de ellos (Imagen IV) ${ }^{13}$, atribuido a Pedro Duque Cornejo, lo inmortaliza en edad más madura, mientras que el otro (Imagen V), bajo la autoria de Juan de la Vega (escuela sevillana) en $1859^{14}$, lo muestra más joven y con una elogiosa cartela que recoge de forma muy breve y con algún error (año de nacimiento) los datos fundamentales de su vida:

13. Protocolo / de el Monasterio de Nra. S. a / Santa María de las Cuevas. / Tomo Primero / Anales en los Tres Primeros Siglos / de su Fundacion. / [...] / Van Insertos los de la Santa Cartuxa de la Purisima Concepcion de Cazalla Fundada / y Dotada por esta de las Cuevas / [... ] / Año de 1744, con colofón de 1745, por el V. P. D. José María Rincón (manuscrito, en fol., con retratos a pluma de los priores de Pedro Duque Cornejo, Madrid, Real Academia de la Historia, Sig. 9-2098). Agradezco al Excmo. Sr. Académico Bibliotecario de la Real Academia de la Historia el permiso de reproducción del retrato ( $p$. 553 del citado Protocolo) y a los facultativos la amabilidad durante la consulta de los fondos.

14. Según consta en la descripción del IAPH, como me informa D. ${ }^{a}$ Nuria Casquete de Prado, Directora de la Institución Colombina, a quien agradezco sinceramente todos los datos sobre el cuadro. De estilo neobarroco, pintura al óleo sobre lienzo y unas medidas de 80x55 cm (y con marco: 94×69×4 cm), como se describe en la citada catalogación, «se trata de una obra imitativa de los retratos antiguos ya que la figura del representado se inscribe dentro de un marco ovalado fingido de tonalidades pétreas, bajo el cual se acoge una leyenda alusiva a su biografía. El protagonista aparece dentro de esta composición vestido con los característicos hábitos blancos de la orden cartuja a la que pertenecía -y de la que fue prior-, recogido en primer plano y de medio cuerpo, estando su cuerpo ligeramente escorado y alzando su rostro anhelante en un gesto propio de la búsqueda de inspiración divina, ya que se halla ante un libro y con una pluma en la mano en disposición de escribir. Tanto su rostro como sus ropajes se hallan bien iluminados y modelados, resultando su aspecto bastante natural. La vinculación de este personaje a la galería retratística de la San- 
Doctor Francisco Galeas; Monje de la cartuja: / Prior en las de Sevilla y Cazalla: / prosista aventajado; versificador facil: miniaturista ingenioso: / Nació en 15 de Agosto de 1566. Murió en 26 de Mayo de $1614 /{ }^{15}$.

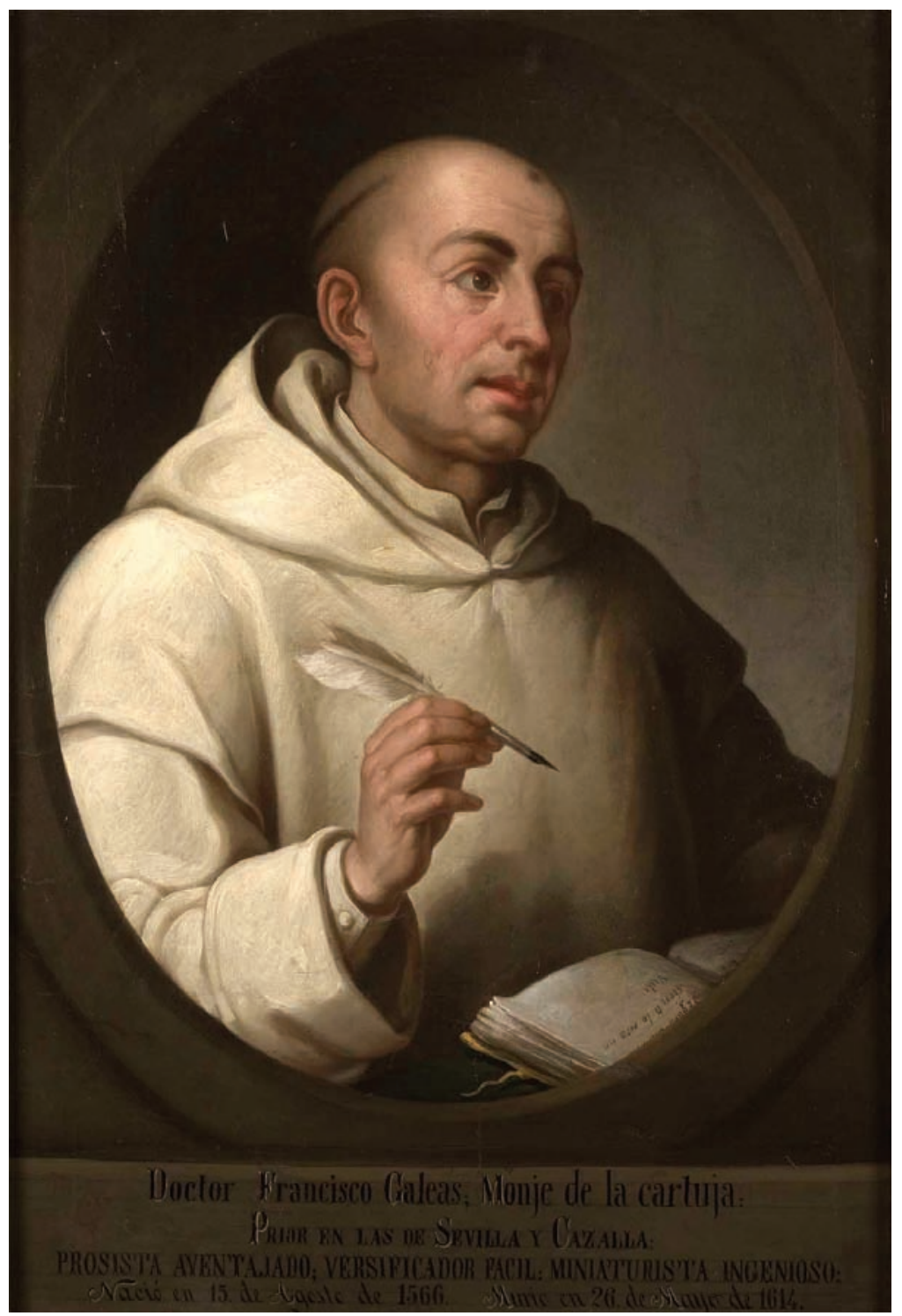

Imagen $\mathrm{V}$

ta Iglesia Catedral viene impuesta por su condición de sevillano ilustre» (Ibídem). Para Francisco Collantes de Terán es «copia del que existía en el Monasterio de Sevilla» («Galería de retratos de sevillanos ilustres que se conserva en la Biblioteca del Excmo. e Ilmo. Cabildo...», p. 172, núm. 18).

15. Institución Colombina, Biblioteca Capitular y Colombina de Sevilla, Retrato de Francisco Galeas. Agradezco a la Sra. Directora de la Institución Colombina el permiso de reproducción del retrato. 
Es decir, un hombre consagrado a Dios en una orden religiosa de observancia severa, cuya vida transcurrió entre la oración / contemplación -como exigían las reglas coventuales - y la escritura / pintura -faceta de miniaturista-. En cuanto al grado de «Doctor» que antecede su nombre en el lienzo, hay eruditos que le atribuyen el doctorado en ambos Derechos, calificándolo de experto jurista en la Audiencia de Sevilla ${ }^{16}$. Sin embargo, en los documentos notariales manejados no aparece nunca con este título, mientras que a su hermano el presbítero Alonso Sánchez Gordillo se le nombra como «licenciado».

Su vinculación con Sevilla, me ha impulsado a investigar en el Archivo Histórico de la Universidad los Libros de Grados mayores y menores en todas Facultades de la Universidad hispalense desde 1579 hasta 1618 sin hallar su colación de «doctor» ${ }^{17}$. Sin embargo, figura la obtención del grado de bachiller en Artes y Filosofía en el Colegio Mayor de Santa María de Jesús y Estudio y Universidad de Sevilla por un tal «Franciscus Sanchez, hispalens[is], in facultate Artium et Philosophiae studens», con fecha de 27 de junio de $1581^{18}$, que plausiblemente pudo ser el nuestro. Otro documento, de fecha anterior, deja constancia de la adecuada preparación que poseía el tal «Francisco Sánchez, hispalense» para la obtención del grado de bachiller en Artes y Filosofía ${ }^{19}$. Se trata de una especie de carta de presentación o certificado de estudios - «sineto»-, dirigido a «llustres jueces», firmada por Jacobo de Valverde, S. J., el 12 de junio de 1581, donde afirma que Francisco Sánchez, hispalense de esta diócesis, ha sido discípulo suyo y ha asistido durante dos años a sus clases de las materias exigidas para obtener el grado en Artes y Filosofía, es decir, las Súmulas de Pedro Hispano, la Dialéctica de Aristóteles y los 4 libros de Física; y en texto infraescrito se dice que Luis de Dueñas y Francisco Gutiérrez, sus

16. Antonio Palomino de Castro y Velasco (1653-1726) lo muestra «como profesor de ambos derechos en el siglo, que continuó siendo abogado de grandes créditos en aquella Audiencia [la de Sevilla]» («El R. P. D. Francisco Galeas, monje cartusiano, pintor», p. 279). Como «doctor en ambos derechos» y ejercitando la abogacía con gran crédito, también lo presenta Juan Agustín Ceán Bermudez (1749-1829), en 1800 (2001, t. II, p. 153). Francisco Collantes de Terán, en 1887, lo denomina «doctor» (p. 172) Ya en el primer cuarto del siglo XX (1922), el erudito Mario Méndez Bejarano (1857-1931), encabeza su biografía loando sus facetas de jurisconsulto, pintor y poeta: «Distinguido jurisconsulto, pintor eminente y poeta de gran reputación». Para él, «se graduó in utroque y ejerció la abogacía en su patria [Sevilla], hasta que se retiró al monasterio de las Cuevas en 1590» (1989 [1922-1925], p. 219). Por citar un último ejemplo, Ildefonso M. Gómez, en 1970, continúa adjudicándole el doctorado en ambos Derechos y la consideración de «uno de los más famosos jurisconsultos de Sevilla» (p. 47).

17. Archivo Histórico de la Universidad de Sevilla (AHUS), Libros 0623 (1579-1581), 0624 (1582-1590), 0625 (1591-1605), 0626 (1605-1618). Dato éste que me ratifica el Dr. D. José Antonio Ollero Pina (Universidad de Sevilla), expertísimo conocedor de la historia de nuestra Universidad durante los siglos XVI y XVII (ver Ollero Pina, 1993), a quien debo y agradezco la localización de los datos sobre Galeas exhumados del AHUS, que expongo a continuación. Igualmente, agradezco a la Dra. D. ${ }^{a}$ Carmen del Camino (Universidad de Sevilla) su ayuda en la lectura e interpretación de esos documentos originales.

18. AHUS, Libro de Grados mayores y menores en todas Facultades desde 1579 hasta 1581, Libro $5^{\circ}$ (Sig. Libro 0623), fol. 217r-v (la cita en fol. 217r).

19. AHUS, Libro primero. Varias certificaciones, títulos, licencias y otras cosas desde 1565 hasta 1642 (Sig. Libro 0766), fol. 116r-v. 
condiscípulos, comprobaron este aserto bajo juramento, en 26 de junio de $1581^{20}$. En nota en la parte superior derecha del citado folio recto, se escribe «graduose». $Y$ en el folio vuelto, leemos: «En 27 junio, Vidal e Piçaño examinaron a Francisco Vázquez [suponemos que error por Sánchez] en bachiller en Artes. Y le aprobaron y sería a las 10 del día y lo graduó Piçaño y juró. Testigos el Dr. Martínez y Patiño». Es decir, estamos ante una especie de resumen de lo que consta en el documento de obtención del grado de bachiller en Artes y Filosofía por Francisco Sánchez, citado más arriba (AHUS, libro 0623, fol. 217r-v). Y en un tercer testimonio, hallamos una síntesis más amplia, en lengua española, de lo contenido en dicho documento redactado en lengua latina:

[En el margen derecho:] Francisco Sánchez. Título a fol. 217.

En el General mayor del dicho collegio, martes veinte e siete de junio de mill e quinientos i ochenta e un años, sería a las dies horas antes del mediodía poco más o menos, el Sr. Maestro Álvaro Piçaño dio e colló el grado de bachiller en Artes y Philosophía a Francisco Sánchez, natural de Sevilla. Testigos: el Sr. Doctor Sebastián .Martínez, Pedro Patiño, bedel, vecinos de Sevilla, y otros. Lo qual fue mediante el sineto del dicho [tachado] Maestro de la Compañía, que le dio i fue comprado [por comprobado], i mediante aver sido examinado por los Sres. Pedro Vidal Clavijo i Maestro Álvaro Piçaño y aprobado por ellos ante el Sr. Rector. I el dicho Francisco Sánchez prestó el sólito juramento ante los Sres. Rector y Consiliarios. Va testado dicho, non vala.

Pasó ante mí, Batolomé Rodrigues notario [Firma y rúbrica] ${ }^{21}$

Por último, en 31 de marzo de 1585, encontramos a un Francisco Sánchez Galeas matriculado en Quinto de Cánones en el Colegio Mayor de Santa María de Jesús, Estudio y Universidad de Sevilla: «Fecho [al margen]. 5. Francisco Sánchez Galeas, natural de Sevilla, juró en último del dicho [es decir, en 31 de marzo de 1586 ${ }^{22}$. Si antes planeaba cierta duda sobre la plausible identificación de Francisco Sánchez Galeas con el tal Francisco Sánchez, debido a tratarse de un nombre y un apellido muy usual, en este caso no hay lugar a dudas de que estamos ante el nuestro. Ello induce a dar más credibilidad a la hipótesis de su identificación con el tal Francisco Sánchez, pues, habiendo obtenido el grado de bachiller en 1581, casi

20. AHUS, Libro primero. Varias certificaciones, títulos, licencias y otras cosas desde 1565 hasta 1642 (Sig. Libro 0766), fol. 116r. Recordemos que, para la obtención del grado de bachiller en Artes por la Universidad de Sevilla, se aceptaban alumnos procedentes del colegio sevillano de la Compañía de Jesús, previa mostración por aquellos de cursos realizados, que se le reconocían, y el correspondiente examen (Ollero Pina, 1993, pp. 506-511).

21. AHUS, Libro de Grados mayores y menores en todas Facultades desde el año de 1579 hasta 1593, Libro $7^{\circ}$ (Sig. Libro 0622), fol. 27r. Precisamente, unas entradas más abajo (fol. $27 \mathrm{v}$ ) se anota la concesión del grado de Licenciado en Artes y Filosofía a su hermano, Alonso Sánchez Gordillo, natural de Sevilla, el 17 de julio de 1581, y se remite a dicho título anotado en fol. 219 [libro 0623, ya citado], donde se encuentra como hemos comprobado (fol. 219r-v).

22. AHUS, Libro de matriculas en todas Facultades desde1578 a 1591, Libro 1 (Sig. Libro 0481), fol. 91v, correspondiente a la sección de Cánones. Los estudiantes juraban en forma «de obedescer a el Sr. Rector in licitis et honestis» (fol. 29r). 
a los 14 años (se bautizó el 31 de agosto de 1567), pudo haberse inscrito en Quinto curso de Cánones en 1586, casi a los 19 años.

El gran crédito del que Galeas gozó como abogado en la Real Audiencia de SeviIla antes de su entrada en las Cuevas según algunos biógrafos, es un extremo que no he podido confirmar, debido a que los fondos documentales conservados de esta institución durante esos años son escasos, fragmentarios y no están estudiados. De cualquier forma, dado que ingresa en el monasterio como novicio en 1589, a los 22 años, resulta demasiado joven para haber adquirido esa fama profesional, que quizá sea uno más de los tópicos propios del género laudatorio. Esta cualificación induce a Regueiro y Reichenberger -junto a los cuatro poemas que figuran en el manuscrito dedicados a celebrar la entrada de Felipe II en Sevilla (1570) - a situar su nacimiento antes de 1550, pues «he would have then been only 23 years old, too young to establish an outstanding reputation in his profession ${ }^{23}$.

Fuera o no doctor Sánchez Galeas, su grado de bachiller en Artes y Filosofía, sus lecturas para ello y su matrícula en Quinto curso de Cánones lo evocan como un hombre culto y hablante latino. A ello, hay que añadir el bagaje que se deduce de su formación como cartujo profeso, los encargos recibidos de sus compañeros de religión, los cargos desempeñados en la Orden, sus escritos, su epitafio, la fama que como poeta y pintor alcanzó en los círculos cultos artísticos y literarios de la Sevilla de la época, y los juicios emitidos por el cartujo José María Rincón en el Protocolo citado, como veremos a continuación, que lo evocan igualmente como hombre de refinada cultura y excelente iluminador.

Respecto a su formación como cartujo, recordemos que, al llegar al Convento de las Cuevas para ser recibido como religioso, el pretendiente a ello -como indica Alonso Sánchez Gordillo- era «examinado en latinidad, que demás ciencias no se procura», y, durante el año de noviciado, el Superior le asignaba un Maestro para que le enseñara

las costumbres de la Orden y las ceremonias particulares y a cantar y rezar el Oficio y Horas Canónicas y que tome de memoria el Salterio para cantar en el Coro, expecialmente para Maytines que se dicen sin luces, y se cantan los psalmos de memoria ${ }^{24}$.

Con motivo de su muerte, el 26 de mayo de 1614, el Protocolo citado ofrece una semblanza de Galeas, de fundamental importancia para reconstruir su etapa conventual ${ }^{25}$. Por ella, conocemos que sus padres y abuelos fueron naturales de Aracena y Cumbres Mayores, ratificando la identidad y morada de sus padres en Sevilla, donde nacieron su hermano el abad Alonso Sánchez Gordillo, de reconocido 
talento, y el propio Francisco Sánchez Galeas ${ }^{26}$. Por primera vez en la documentación consultada, se le atribuyen a éste estudios de Jurisprudencia, mostrándolo como uno de los más célebres abogados de Sevilla:

quien, siguiendo la Jurisprudencia, llegó a ser uno de los más célebres abogados de Sevilla, pero enamorado de la soledad y quietud que gozan los que solo aspiran a el Uno necesario, despreció las esperanzas que le daban los Baldos y Pandectas, por la seguridad prometida a los que abrazados con la cruz siguen a Cristo ${ }^{27}$.

Durante el tiempo libre, en el silencio y soledad de su celda, Galeas debíó escribir y continuar cultivándose ${ }^{28}$. Tras los seis años de profeso, en 1596, los padres conventuales decidieron

dar ejercicio a sus talentos y a la rara habilidad de su pluma, haciéndole que ordenase los papeles del Archivo y escribiese el libro Becerro' 29 [...]. Acabada ésta, dejó otras memorias de la excelencia que el arte de minar tenía en el libro del Mandato, que se nos muestra el día de las Reliquias ${ }^{30}$, y en otras dos láminas de un Niño desnudo y Nuestra Señora, que veneramos en la Sacristía [...] $]^{11}$. Escribió un libro de hieroglíficos, parte en verso y parte en prosa. Compuso una Josefina en verso y otros algunos dípsticos sueltos, que todos ellos son testimonios de su perspicaz ingenio, elocuencia y poesía castellana y latina ${ }^{32}$.

26. Rincón,Protocolo / de el Monasterio de Nra. S. a / Santa María de las Cuevas. / Tomo Primero / Anales en los Tres Primeros Siglos / de su Fundacion. / [...], p. 567 col b.

27. Rincón, Protocolo / de el Monasterio de Nra. S. a / Santa María de las Cuevas. / Tomo Primero / Anales en los Tres Primeros Siglos / de su Fundacion. / [..., p. 567, col. b. Aunque Cuartero y Huerta (1988) utiliza este Protocolo como fuente muy importante para su estudio, lo cual he tenido en cuenta, leo y cito directamente por el original. En las citas literales, modernizo la grafía del siglo XVIII según las normas actuales.

28. Sobre la capacidad, forma y utensilios de la celda de un monje cartujo y, en cierta medida, la holgura de la vida conventual, ver Sánchez Gordillo, 2003 [1663], pp. 355-357.

29. Refundición del primer libro Becerro, «ampliado con numerosas noticias importantes para la historia del monasterio», que, a su vez, fue redactado de nuevo, en 1744, «por el V. P. don José Martín Rincón, que terminó su labor en marzo de 1745» (Cuartero y Huerta, 1988, t. I, p. 60).

30. Inutilizado en «la inundación del Guadalquivir en el año de 1784» (Cuartero y Huerta, 1988, t. II, p. 626).

31. A ellos, se añaden otros «dos cuadritos, de miniatura, que representaban a Nuestro Señor Jesucristo muerto y su Resurrección, colocados en el altar de las reliquias (Cuartero y Huerta, 1988, t. II, p. 626). A la destreza artística de Galeas también se debe «casi con toda seguridad -en palabras de Álvarez Márquez (2013) - la iluminación y probablemente también la escritura del Evangeliarium secundum Ordinem Cartusiensem, hoy conservado en la Biblioteca Colombina y Capitular (Ms. 58-6-20)» (p.183). Para la descripción de este bellísimo ejemplar, ver Álvarez Márquez (2013, pp. 183-184) y, para más numerosos detalles, consultar la base de datos de la Biblioteca Colombina y Capitular de Sevilla, a cuya Directora agradezco la información que al respecto me ha facilitado, y, en particular, Álvarez Márquez (1998, pp. 394-395).

32. Rincón, Protocolo / de el Monasterio de Nra. S. a / Santa María de las Cuevas. / Tomo Primero / Anales en los Tres Primeros Siglos / de su Fundacion. / [...] p. 568 col. a. 
De sus dotes de gobierno, severidad y disciplina, fue muy consciente su orden religiosa, eligiéndolo en 1604 prior de las Cuevas ${ }^{33}$, siendo «absuelto» -'depuesto'- en septiembre de 1607, en acto de visita por el P. D. Juan de la Cruz, prior de Cazalla ${ }^{34}$. El año de 1605 había sido nombrado «Convisitador de la Provincia» y «Visitador de las Cartujas de Portugal», comisión que tuvo efecto en el año de 1606. Derribado por sus antagonistas, celosos de su valía ${ }^{35}$, el Padre Galeas se trasladó como conventual al monasterio de la Cartuja en Cazalla, donde le instituyeron «Rector» y «Prior» hasta que tres años después, 1612, lo volvieron a absolver en acto de visita ${ }^{36}$. Como ya hemos indicado, el 26 de mayo de 1614, casi a los 48 años de edad, le sorprendió la muerte. Para loar sus virtudes y vida observante y penitente, el autor del Protocolo elige precisamente el elogio que escribe en el Libro de Anniversariae uno de sus más acérrimos perseguidores, el P. D. Francisco Caravaca:

D. Franciscus Galeas, professus et Prior huius domus et domus de Cazalla, et convisitator huius Provintiae, Religiossus altissime orationis et contemplationis, magne obseruantie et poenitentie, qui cum esset ingenio acutissimus et a Domino multis donis naturalibus et acquisitis dottatus ex ipsis donis et gratiis multa cumula meritorum patientie et tolerantie a fratribus suis comproffessis ei prouenerunt, obiit $1614^{37}$.

Epitafio reproducido anteriormente -con algunas variantes - por el abad Alonso Sánchez Gordillo en su Svmaria relación del insigne Monasterio..., cuando, al señalar la comodidad para la vida humana que se respiraba en el convento, aludía a que tampoco estaba exenta a veces de envidias y otras pasiones, citando el caso del P. Galeas «a quien quitaron la vida con disgustos los mismos que debían estimarle, y ellos mismos fueron sus jueces y, sintiendo su falta, le pusieron este epitafio» ${ }^{38}$. Tanto Sánchez Gordillo como Rincón, después de citar el epitafio, reivindican la memoria del religioso, a través del reconocimiento que le dispensó su

33. Rincón, Protocolo / de el Monasterio de Nra. S. a / Santa María de las Cuevas. / Tomo Primero / Anales en los Tres Primeros Siglos / de su Fundacion. / [...], p. 556 col. a.

34. Rincón,Protocolo / de el Monasterio de Nra. S. a / Santa María de las Cuevas. / Tomo Primero / Anales en los Tres Primeros Siglos / de su Fundacion. / [...], p. 560, col. a.

35. A este respecto, leemos en Cuartero y Huerta: «El P. Galeas era varón de muy ventajosas prendas y de agudísimo ingenio, acompañado de excelentes virtudes y de vida austera y observante, por lo cual no era posible que le faltaran émulos o contradictores» (t. I, 1988, p. 576).

36. Rincón, Protocolo / de el Monasterio de Nra. S. a / Santa María de las Cuevas. / Tomo Primero / Anales en los Tres Primeros Siglos / de su Fundacion. / [...], pp. 560-561 y 565.

37. Rincón, Protocolo / de el Monasterio de Nra. S. a / Santa María de las Cuevas. / Tomo Primero / Anales en los Tres Primeros Siglos / de su Fundacion. / [...], p. 568, cols. a-b, cuya traducción agradezco a la Dra. D. ${ }^{a}$ Leonor Molero Alcaraz (Universidad de Sevilla):

Don Francisco Galeas, profeso y prior de esta casa y de la casa de Cazalla, convisitador de esta Provincia, religioso de altísima oración y contemplación, de gran observancia y penitencia, quien, aun cuando era agudísimo de ingenio y estaba dotado por el Señor con muchos dones naturales y adquiridos, de estos mismos dones y gracias le sobrevino un gran cúmulo de méritos a la paciencia y a la tolerancia por sus hermanos compañeros de Orden. Se fue en 1614

38. Sánchez Gordillo, 2003 [1663], pp. 371-372. 
propia Orden, pues, en la carta de difuntos del Capítulo General de 1615, «premió sus méritos, concediéndole pleno Monachado y Missa de Beata Maria, per tot]um] ord[inem], y anniuersario perpetuo» ${ }^{39}$.

Las excelencias de Galeas en el arte de la escritura y la pintura fueron reconocidas, además de por su propio hermano y por los miembros de su orden monástica, por la culta Sevilla coetánea y de siglos posteriores. Así, Francisco Pacheco (15641644), «amigo de la cultura y de los hombres cultos, un infatigable trabajador, un notario fiel y pulcro» como lo adjetiva Bassegada ${ }^{40}$, lo cita en su Arte de la Pintura (1649) entre otros excelentes religiosos iluminadores ${ }^{41}$. Ya en el siglo XVIII, 1724, Palomino de Castro y Velasco lo biografía como pintor eminente, «no dejando de aplicar los ratos ociosos [...] a el Arte de la Pintura, de cuya dulce violencia era atraído por una propensión natural, y la cursó, a lo que se entiende, en la erudita y virtuosa escuela del gran Luis de Vargas», aludiendo también a su alta calidad como escritor en verso y en prosa, y concediendo especial atención a un Hebdomadario «de oraciones pertenecientes a cada misterio y solemnidad, con las esfigies de los santos o historias sagradas, ejecutadas de su mano con singularísimo primor y delicadeza de pincel muy diestro» ${ }^{42}$. El neoclásico Juan Agustín Ceán Bermúdez, que en su biografía de Galeas lo presenta como «pintor de iluminación o de miniatura», corrige a Palomino en cuanto a su aprendizaje del arte de la pintura bajo la dirección de Luis de Vargas, pues éste había fallecido en 1568, sin indicar ninguna otra escuela ${ }^{43}$. Otros eruditos de los siglos XIX y XX continuarán incluyendolo y loándolo en sus respectivas recopilaciones, como por ejemplo Méndez Bejarano (1922-1925) ${ }^{44}$, y repitiendo aciertos y falsedades de compiladores anteriores ${ }^{45}$.

El estudioso que recoge con mayor precisión la labor de escritura de Galeas, la faceta que aquí más nos interesa, es Ildefonso M. Gómez ${ }^{46}$, en la siguiente enumeración:

- Vida del glorioso San José, en versos castellanos. No se imprimió.

- Tratado de jeroglíficos, en prosa y verso, e ilustrados por el autor.

- Libro del Mandato, iluminado y miniado por su mano. Quedó destruido en la inundación de 1784.

- Libro Becerro o Protocolo, refundido y nuevamente redactado por por el P. Rincón, como ya se ha indicado. En la cartuja Aula Dei, existe una copia parcial del mismo.

39.Sánchez Gordillo, 2003 [1663], p. 372, y Rincón, 1744-1745, p. 568, col. b, a quien pertenece la cita. 40. Bassegada i Hugas, «Introducción», 2001, pp. 11-12.

41. Pacheco, Arte de la Pintura, p. 220.

42. Palomino de Castro y Velasco, «El R. P. D. Francisco Galeas, monje cartusiano, pintor», pp. 279-280

(la primera cita en p. 289 y la segunda en p. 280).

43. Ceán Bermúdez, 2001 [1800], t. II, pp. 153-154, p. 153.

44. Méndez Bejarano, 1989 (1922-1925), pp. 219-220.

45. Ver «Galeas, Francisco», en Archivo biográfico de España, Portugal e Iberoamérica, ABEPI I, II, III, 1986-1998, I, p. 358, 161-173; II, 367, 336-337; III, 251, 183-184.

46. Gómez, 1970, p. 67. 
- Relación del traslado de los restos del arzobispo de Sevilla, don Gonzalo de Mena, desde la Santa Iglesia Metropolitana hasta la cartuja de las Cuevas. «Existe copia de esta obra -leemos en Ildefonso M. Gómez- en el libro de Acaecimientos dignos de memoria, en el que se reunieron copias de varios documentos, cuyos originales posee el señor Marqués de San José de la Serra».

- Otras composiciones poéticas ${ }^{47}$.

De ellas, son estas «composiciones poéticas», citadas en último término y de forma tan vaga, las que focalizarán nuestra atención, limitándonos a la producción dramática, radicada en la Biblioteca de la Hispanic Society of America e inédita hasta ahora. No se trata de una obra abundante ni caracterizada por su excelencia, pero, dada la época en la que vivió su autor, unos años de experimentación teatral en los diversos frentes de la práctica escénica, donde conviven escritores y actores «amateurs» y profesionales, y en los que fueron muchas las obras perdidas, creemos oportuna su exhumación, por añadir una tesela más a ese mosaico de nuestro arte dramático durante el último tercio del siglo XVI y principios del siglo XVII.

Catalogadas por Regueiro y. Reichenberger (Ms. HC380/611)48, no solo me interesaron por su carácter inédito y su valor intrínseco sino también porque una de ellas, la Representaçion del nasçimiento de lesuchristo Saluador nuestro, era, con variantes, la segunda pieza del Ms. B2603 (B2603/2), radicado igualmente en la Hispanic Society of America, que había descrito y analizado en un artículo anterior ${ }^{49}$. He aquí la relación de las citadas piezas: $21 r)$.

- Representaçion breue para el dia del / Sanctissimo Sacramento [...] (fols. 20r-

-Yntroito para representaciõ a la ue- / nida del III. ${ }^{\text {mo }}$ arçobispo de Seuja [...] (fols. 94r-95r).

- Para la festiuidad del nascimi. ${ }^{\text {to }}$ de / Nuestro Saluador / y pazes fechas en la discordia entre for- / taleza y flaqueza (fols. 95v-103v).

- La historia de quando Abrahã / echo de casa a ysmael, y / Agar Su madre (fols. 105r-109v).

- Comedia yntitulada Triumpho / de' pobreza contra / Riqueza (fols. 110r-132r).

- Representaçion del nasçimiento / de lesuchristo Saluador nuestro (fols. 135r165r), precedida por un Introito para la comedia [...] (fols. 132v-134v).

- Dialogo de dos pastores / el uno llamado / Siluano, y el / otro alegria (fols. $173 r-177 v)^{50}$.

47. Gómez, 1970, p. 57, en la que se encuentra la cita

48. 1984, vol. I, pp. 221-238.

49. Reyes Peña, 2005, pp. 319-343.

50. Regueiro y Reichenberger, 1984, vol. I, pp. 224-225, donde ofrece la catalogación detallada de cada una, que aquí omito, pp. 226-238. Reproduzco los títulos por el manuscrito. 
El manuscrito que las contiene es de formato folio, con cubierta de pergamino y anotación a lápiz: «Manuscr» [con letra muy grande] ${ }^{51}$. En el lomo, se lee: «P. Galeas. / Poesias es- / pirituales. / M.S. / Siglo 16», como describen Regueiro y Reichenberger $^{52}$. Las hojas de guarda son de un papel diferente a las del resto del manuscrito y tienen filigranas (un caballero con lanza enfrente de un toro). El papel del ms., según Rodríguez Moñino y Brey Mariño, es de fines del XVII53. La tinta es marrón sepia oscuro. El ms. está falto de una primera hoja que parece arrancada (¿era la portada?). La numeración de los folios empieza en el número 1 de tinta diferente. Los cuatro primeros folios tienen además otra numeración (Ai-Aiiij). En la contraportada, a lápiz: «A.R. I / Vitr 18» / MANUSCRIPT [sello rojo] / AC 350/6 CXXXIX [a lápiz]. Hay un folio pegado y escrito a máquina: «Galeas, Fr. o Cart., poesías espirituales y representaciones sacras dramáticas del P. Fr. Francisco Galeas, monje de la Cartuja de Sevilla, en El siglo XVI ${ }^{\circ}$. Manuscrito inédito, en papel de fines del siglo XVII . En fol. mayor. Perg. ant. 200 hojas num. M. 1000» ${ }^{54}$.

En la hoja de guarda hay dos notas, escritas por manos y tintas diferentes. Fechadas en el siglo XIX, descubren a poseedores del ms. en dos momentos puntuales de su historia: 1838 y 1895. La primera lo adjudica al P. Galeas, remitiendo a su vez a otra obra suya, los Jeroglíficos morales:

1) «Poesías espirituales del / P. D. Fran ${ }^{\mathrm{co}}$ Galeas monje / de la Cartuja de Sevilla. / Véase la obra de ese mis- / mo autor que se intitula: Hiero- / glificos morales que M.S. ecsiste entre / mis libros. Sevilla, 10 de Junio 1838 / J. Colón». 2) «Al Excmo. Sr. D. Antonio Cánovas del Castillo / como cariñosa prueba de respetuosa ad- / miración. Mane de Lara / y Alcalá / Marzo 1895» ${ }^{55}$.

Para Regueiro y Reichenberger, la fecha del manuscrito es incierta, refiriendo tres postuladas por distintos investigadores: 1690; «letra de principios del siglo XVII o muy finales del $X V \mid » ;$ o hacia $1700^{56}$.

A estas alturas de nuestro acercaniento a Francisco Galeas y su obra dramática, se impone dar a conocer esas siete piezas, cuya condición de inéditas hace indispensable su presentación pormenorizada: encabezamiento completo, figuras que intervienen, forma expresiva, extensión y métrica, argumento, estructura, género,

51. Agradezco al Dr. D. John O'Neill, Director de la Sección de Manuscritos y Libros Raros de la Biblioteca de The Hispanic Society of America, su amabilidad al enviarme microfilm del citado manuscrito y autorizarme la publicación de la producción dramática de Galeas.

52. Regueiro y Reichenberger, 1984, vol. I, p. 223.

53. Rodriguez Moñino y Brey Mariño, 1965, vol. II, p. 572.

54. Estas referencias van seguidas de una larga nota en alemán, también escrita a máquina, donde se da noticias del ms. («Manuscrito español, muy limpio y con letra itálica»), su datación y autor («Aproximadamente de 1690 del poeta Francisco Galeas, según Ticknor y Salvá»), y de su contenido, así como de poseedores, según las noticias de la hoja de guarda. Agradezco a la Dra. D. ${ }^{a}$ María del Valle Ojeda Calvo la descripción detallada del manuscrito realizada durante su visita a la Hispanic Society of America, así como la comprobación in situ de algunas lecciones no claras en el microfilm del mismo que he manejado.

55. Regueiro y Reichenberger, 1984, vol. I, p. 223. a la que pertenecen ésta y la cita anterior.

56. Regueiro y Reichenberger, 1984, vol. I, p. 224. 
teatralidad y finalidad de escritura, que ofreceremos respetando el orden en el que aparecen en el manuscrito ${ }^{57}$.

I

ENCABEZAMIENTO: Representación breve para el día del Santísimo Sacramento y represéntase al pasar del Santísimo Sacramento por alguna calle y es entre David y Micol, y él ha de estar en un tablado con su arpa tañendo y bailando y la Micol en una ventana que venga sobre el tablado (fols. 20r-21r).

FIGURAS: David y Micol.

FORMA EXPRESIVA, EXTENSIÓN Y MÉTRICA: Escrita en verso, con una extensión de $49 \mathrm{vv}$. octosílabos, agrupados en una redondilla de rimas consonantes cruzadas (ABAB) y nueve quintillas de rima $A B B A B$.

ARGUMENTO: Micol, ofuscada, se dirige desde una ventana al rey David, que tañe y danza ante el paso del Sacramento por una calle, para advertirle de la inconveniencia de actuar como juglar, siendo rey, y de la deshonra que acarreará esa humilde acción ante el pueblo a su linaje. David le responde que humillarse ante Dios, como él hace, no es caer sino levantar.

GÉNERo: Auto de tema bíblico, Antiguo Testamento, basado en el episodio del menosprecio y burla de Micol a su esposo David, cuando desde una ventana lo ve llegar danzando ante el arca de la alianza de Yahvéh en el traslado a su ciudad. David le recrimina su actitud y Dios la castiga con la esterilidad (2Sam 6, 16, 20-23, IPar 15, 29). La alusión eucarística explícita solo aparece en el título del auto, pero esa representación en un tablado con una ventana sobre él, en coincidencia con el paso real del Sacramento, confiere a la pieza valor eucarístico prefigurativo. Recordemos que, tras depositar David el arca en el tabernáculo que había construido para ella, ofrece a Yahvéh holocautos y sacrificios eucarísticos (2Sam 6, 17, IPar 16, 1-2). Conviene advertir cómo un elemento de la realidad externa a la ficción -la presencia del Sacramento - se incorpora a ella y completa el sentido de la pieza.

TEATRALIDAD: El paratexto correspondiente al título y las acotaciones implícitas muestran a Galeas como dueño de la puesta en escena: David, ataviado humildemente como un juglar y acompañado por un instrumento musical -arpa- tañe y danza sobre un tablado al paso por la calle del Santísimo Sacramento. Micol lo observa desde una ventana que cae sobre el tablado y se dirige a él, comenzando entre ambos el diálogo.

57. A partir de ahora, en los encabezamientos de las piezas y en las citas de ellas modernizaremos de acuerdo con los criterios actuales, respetando las características propias de la lengua de la época en los tres niveles del signo linguístico y manteniendo las contracciones frecuentes del momento, como dello, deste, destos, etc. Al desear respetar la forma de pronunciación de la época, soy consciente de que no siempre se puede estar seguro al 100\%; por ello, en los casos de duda mantengo las formas tal como figuran en el ms. Agradezco al Dr. D. Rafael Cano Aguilar (Universidad de Sevilla), sus acertadas observaciones sobre aspectos relativos a historia de la lengua. 
FINALIDAD: La brevísima pieza está escrita para la celebración de la festividad del Corpus Christi - día de público homenaje a la Eucarístía con el recorrido procesional del Sacramento por calles- y propósito laudatorio y aleccionador.

II

ENCABEZAMIENTO: Introito para representación a la venida del Ilustrísimo Arzobispo de Sevilla después de mucha absencia de prelado en ella (fols. 94r-95r).

FIGURAS: Un recitante.

FORMA EXPRESIVA, EXTENSIÓN Y MÉTRICA: Escrito en verso, con una extensión de $50 \mathrm{Vv}$., agrupados en diez estrofas de 5 versos endecasílabos con rima consonante en $2^{\circ}$ y $5^{\circ}$ versos (ABCDB), que cambia de estrofa en estrofa ${ }^{58}$.

ARGUMENTO: La ciudad recibe con gozo a su arzobispo, el cual como pastor la adoctrinará y como padre amante la protegerá; y, agradecida, ordena la representación de una comedia en su servicio. Unos versos de captatio benevolentiae cierran la pieza.

GÉNERO: Introito monologado de tono serio que precede la representación de una comedia, cuyo título y argumento no se indican.

TEATRALIDAD: La metateatralidad propia del género queda perfectamente reflejada en los versos finales de la pieza:

\author{
Agradecida, pues, de tantos bienes, \\ para demonstración de su alegría, \\ no sin grande razón nos ha mandado \\ que recitemos hoy esta comedia \\ en servicio de vuestra Señoría; \\ y, así, le suplicamos de rodillas \\ se sirva de la oír, favoreciendo \\ con el auctoridad de su presencia, \\ y las faltas que en ella(s) se sintieren \\ como señor y padre corrigiendo (vv. 41-50).
}

FINALIDAD: Pieza de circunstancias escrita para celebrar la llegada del arzobispo de Sevilla, como se indica en su encabezamiento, a través de sus benéficos efectos, que propician la loa del prelado. La súplica de atención y corrección de posibles faltas completan la finalidad de este tipo de piezas introductorias a la representación de la comedia. Sobre el posible arzobispo al que pudo estar dedicada la obra, hay tres que pastorean la diócesis hispalense en vida y años de Galeas en que pudo componerla: Rodrigo de Castro y Osorio (tomó posesión por poderes el 15 de febrero de 1582 e hizo su entrada en la ciudad a principios de noviembre de 1582 , falleciendo el 18 de septiembre de 1600); Fernando Niño de Guevara (tomó pose-

58. Respecto a su métrica, nuestro Introito difiere de las estrofas habituales en este tipo de piezas: coplas de pie quebrado y quintillas, con predominio del romance cuando impera la palabra «loa» y utilización de la redondilla en el caso de las dialogadas (Flecniakoska, 1975, p. 47). 
sión por poderes el 18 de junio de 1601 y efectuó su entrada en la ciudad el 13 de diciembre de 1601, muriendo el 8 de enero de 1609); y Pedro de Castro y Quiñones (preconizado el 5 de julio de 1610, hizo su entrada en Sevilla el 6 de diciembre de 1610, falleciendo el 20 de diciembre de 1623). Todos desde sus nombramientos tardan en entrar en la ciudad, siendo Rodrigo de Castro y Osorio quien más se dilata y más largas estancias realiza fuera de la diócesis ${ }^{59}$.

III

enCABeZAMIENTo: Para la festividad del nacimiento de Nuestro Salvador y paces fechas en la discordia entre Fortaleza y Flaqueza (fols. 95v-103v).

FIGURAS: Fortaleza y Flaqueza, caracterizados como pastores sin signos de comicidad ni en su lenguaje ni actuación. Solo en los versos que reproducimos más abajo muestran cierta rusticidad propia de su condición pastoril.

FORMA EXPRESIVA, EXTENSIÓN Y MÉTRICA: Pieza escrita en verso: 248 VV., agrupados en 45 quintillas octosilábicas con rima consonante y el mismo esquema $(A B B A B)^{60}$; más 8 villancicos, distribuidos entre ellas: 6 formados por tres versos octosílabos con rima consonante y la misma disposición (ABB); otro de tres versos, el segundo quebrado (8A 4B 8B); y otro de dos versos octosílabos pareados (8A $8 \mathrm{~A})$. Es decir, se trata de una pieza donde se combina la recitación y el canto.

ARGUMENTO: El villancico inicial sintetiza el contenido de la obra:

$$
\begin{aligned}
& \text { Dos pastores diferentes } \\
& \text { hacen a costa de Dios } \\
& \text { las paces entre los dos (vv. 1-3). }
\end{aligned}
$$

La pieza escenifica una disputa entre los personajes Fortaleza y Flaqueza, cuando el segundo desea hacer las paces con el primero, que se resiste por sus opuestas naturalezas. Sin embargo, queda convencido al argumentar Flaqueza que ya es posible, debido a la encarnación del Verbo divino en virginales entrañas, pues con la carne el Verbo pagará a Dios la deuda del hombre. Ambos finalizan la obra, dirigiéndose a la Virgen para ofrecerle la vida. Un villancico en loor de la encarnación de Cristo pone fin a la pieza:

$$
\begin{aligned}
& \text { Por amores del humano, } \\
& \text { humano nacéis, Señor, } \\
& \text { bendito sea vuestro amor (vv. 246-248). }
\end{aligned}
$$

GÉNERO: Auto alegórico en su tema y personajes.

59. Las biografías de estos sucesivos arzobispos, en Ros, 1986, pp. 151-161, 165-169, y 169-175, respectivamente, de donde tomo los datos ofrecidos.

60. A la formada por los vv. 236-240, le faltan los dos primeros versos, que hemos contabilizado. 
TEATRALIDAD: Enfrentamiento dialéctico entre dos personajes de opuesta naturaleza, con amenaza incluso de llegar a las manos, pero que se aplaca y resuelve cuando uno de ellos cede a las peticiones del otro:

\begin{tabular}{|c|c|}
\hline FORTALEZA & ¡Pues a las manos, pastor! \\
\hline FLAQUEZA & ¡A las manos y a los pies! \\
\hline FORTALEZA & $\begin{array}{l}\text { ¡Más crianza, descortés, } \\
\text { que vos por ganar honor } \\
\text { veréis cómo lo perdéis! }\end{array}$ \\
\hline FLAQUEZA & ¡Ya no es posible perder! \\
\hline FORTALEZA & ¡Pues no es posible ganar! \\
\hline FLAQUEZA & $\begin{array}{l}\text { Posible es para mostrar } \\
\text { que, pues vos tenéis poder, } \\
\text { a mí no puede faltar. }\end{array}$ \\
\hline FORTALEZA & $\begin{array}{l}\text { ¡No hay ventaja conocida, } \\
\text { vamos a brazo partido! }\end{array}$ \\
\hline FLAQUEZA & $\begin{array}{l}\text { ¡Vamos! ¡Ternás entendido } \\
\text { que mi fuerza está crecida } \\
\text { y tu poder no ha crecido! }\end{array}$ \\
\hline FORTALEZA & ¡Suso, los brazos asidos! \\
\hline FLAQUEZA & ¡Suso!, pues que tú lo quieres. \\
\hline FORTALEZA & ¿Qué harás? \\
\hline FLAQUEZA & Lo que hicieres. \\
\hline FORTALEZA & Pues, mira, no des gemidos. \\
\hline FLAQUEZA & No daré, si no los dieres. \\
\hline FORTALEZA & $\begin{array}{l}\text { Flaqueza, ya no haya más, } \\
\text { que me cansas. ¡Déjame! }\end{array}$ \\
\hline FLAQUEZA & $\begin{array}{l}\text { Ni un punto te dejaré, } \\
\text { si primero no me das } \\
\text { lo que yo suplicaré (vv. 118-142) }\end{array}$ \\
\hline
\end{tabular}

FINALIDAD: Auto para la celebración del nacimiento de Cristo con propósito doctrinal sobre el misterio de la encarnación en el seno de la Virgen María por amor del Verbo Divino y sus benéficas consecuencias para el género humano.

\section{IV}

ENCABEZAMIENTO: La historia de cuando Abraham echó de casa a Ismael y Agar, su madre (fols. 105r-109v).

FIGURAS: Ismael, Isaac/Isac, Sarra, Abraham, Ángel. 
FORMA EXPRESIVA, EXTENSIÓN Y MÉTRICA: Pieza escrita en verso: 224 Vv., agrupados en 44 quintillas octosilábicas con rima consonante y el mismo esquema (ABABA) más una redondilla (8A 8B 8A 8B: vv. 91-94)61. La pieza aparece segmentada en tres partes, produciéndose un vacío de personajes en el paso de la segunda a la tercera:

[Primera parte]: vv. 1-85 = 85 vv.

Segunda parte: vv. 86-159 = 74 vv.

Tercera parte: $160-224=65 \mathrm{vV}$.

ARGUMENTO: Ismael se dirige a su hermano Isaac, instándole a aprovechar el tiempo presente de la niñez para disfrutar de placeres, pues después habrá tiempo de enmendarse. Ante las reconvenciones de Isaac, aquél le obliga a jugar a los repelones y, al negarse su hermano, le da dos torniscones. Sarra, esposa de Abraham y madre de Isaac, reprende a Ismael y se lamenta de los sufrimientos que padece por culpa de él y de su madre, la esclava Agar. Abraham, al hallar apesadumbrada a su esposa, le pide explicaciones y ella, tras confesarse quejosa de él y afrentada por Agar, lo incita a poner solución al conflicto. Las razones de Abraham en favor del amor que le profesa no la convencen y lo apremia a expulsar de su casa a Agar y a Ismael. Abraham, dividido entre el mandato de Sarra y el amor hacia Agar y su hijo Ismael, pide ayuda divina. Un Ángel le comunica que Dios así lo ordena y que amparará al niño. Abraham acata el mandato divino y bendice a Dios por templar con dulzura lo agrio de su dolor.

GÉNERO: Auto histórico bíblico del Antiguo Testamento, que dramatiza con cierta crudeza y realismo el pasaje del destierro de Agar y su hijo Ismael por Abraham, ante las quejas de Sara por el comportamiento de Ismael con Isaac y de Agar con ella (Gén XXI, 9-13). El autor humaniza a los personajes en sus actitudes y sentimientos, creando tensión entre ellos y en ellos mismos. El lenguaje se caracteriza por su sencillez, cercanía y concisión. Estas cualidades, su breve extensión y el hecho de ser un tema bíblico muy poco tratado en el teatro español, como advierte Léo Rouanet al examinar el Auto del destierro de Agar del Códice de Autos Viejos hasta el punto de afirmar: "Je ne connais pas en Espagne d'oeuvre dramatique composée sur le même sujet» ${ }^{62}$, han aconsejado su elección para incluirlo en Apéndice, facilitando al lector una pieza completa de Galeas (véase Apéndice).

TEATRALIDAD: Si bien Rouanet, a propósito del auto del CAV y de la escasísima presencia de este tema en nuestro teatro, escribe que «l'histoire d'Agar et d'Ismael se prète d'ailleurs assez mal à une action théâtrale. Si notre poète a su se montrer émouvant, c'est grâce à sa naiveté et a sa concision» ${ }^{63}$, nuestro autor, en 248 versos, correspondientes a 100 del auto del CAV (vv. 99-150, pues éste avanza más

61. El último verso de esta redondilla está añadido con diferente mano y tinta para subsanar un olvido de copia. Al tener sentido como redondilla y no saber si en su origen fue una quintilla, la he dejado tal cual, sin contabilizar al auto un verso más.

62. Rouanet, 1901, t. IV, pp. 143-144

63. Rouanet, 1901, t. IV, p. 143.

HIPOGRIFO, 5.1, 2017 (pp. 115-154) 
en la historia de Agar e Ismael), logra dotar de tensión a la pieza y construir unos personajes de mayor talla dramática y conflictiva que sus homónimos del CAV. La falta de acotaciones escénicas explícitas y la escasez de las implícitas inducen a aventurar una muy sencilla puesta en escena.

FINALIDAD: Aleccionadora, como es habitual en este tipo de obras, sin que sepamos para qué ocasión se compuso. Quizá, por comparación con el otro auto de tema bíblico veterotestamentario del autor, fue para su representación en la festividad del Corpus, pero, a diferencia del anterior, en éste no hay referencias eucarísticas ni explícitas ni implícitas.

V

encAbeZAmiento: Comedia intitulada Triunfo de Pobreza contra Riqueza (fols. 110r-132r).

FIgURAS: Mundo, Riqueza, Pobreza, Simplicidad, Sosiego, Solicitud, Curiosidad, Dos Truhanes, Ángeles, Pastores.

FORMA EXPRESIVA, EXTENSIÓN Y MÉTRICA: En prosa, con una extensión aproximada de 653 líneas, más 65 vv., más dos breves textos latinos. Escrita con un lenguaje sencillo, la prosa aparece seccionada por una serie de versos cantados: dos villancicos de 3 versos (8A 8B 8B); un villancico de 6 versos (8A 4A : 8A 8A 4A : 8A); un villancico de 4 versos (6a 6B 6a 6B); un villancico de 3 versos (9A 5A : 9A); un villancico de 2 versos (11A 11A); un villancico de 6 versos (12A 12A : 11B 11B 12A: $12 \mathrm{~A})$; un villancico de 7 versos (8a $7 \mathrm{a}: 8 \mathrm{~B} 8 \mathrm{~B} 8 \mathrm{~B} 8 \mathrm{a}: 7 \mathrm{a}$ ); dos villancicos de 4 versos con la misma disposición de rimas (6A 6B 6C 6B y 7A 7B 7C 7B); un villancico de tres versos (6A 6B 7B); un villancico de 5 versos ( $8 \mathrm{~A} 6 \mathrm{~b} 6 \mathrm{~b} 6 \mathrm{~b} 6 \mathrm{~A}$ ); y cuatro tercetos encadenados. En total, un conjunto de 62 versos cantados. A ellos, hay que añadir una letra de 3 versos octosílabos (ABB) y dos breves textos cantados en lengua latina, presentes en las ceremonias litúrgicas del cuarto domingo de Adviento: «Veni, Domine, et noli tardare. / Ostende faciem tuam, et salvi erimus» (fol. 131v) [el segundo de ellos localizado en Sal, 79, 4, 8 y 20].

La pieza está segmentada en cuatro partes, separadas por el vacío de personajes:

En la PRIMERA PARTE se introducen Mundo y Riqueza (fol. 110r).

SEGUNDA PARTE en que se introducen la Pobreza, y Simplicidad y Sosiego, sus hijos, y entran cantando (fol. 112v).

TERCERA LICIÓN, en que se introducen Solicitud, Curiosidad y Riqueza, y dos truhanes (fol. 116V).

CUARTA PARTE en que entra Pobreza con Sosiego y Simplicidad, sus hijos, cantando, y adelante entra la Riqueza (fol. 126v).

ARGUMENTO: Riqueza, sabedora de la venida del más alto y más poderoso señor que tiene la tierra, pide ayuda a su padre el Mundo para, con su favor, aparejarle la 
más alta y la más rica posada. El Mundo, conocedor de que esa misma noche su hija Pobreza recibe en ese lugar a dicho huésped, le aconseja que haga dos cosas: preparar un rico aposento e ir a visitar a su hermana Pobreza para enterarse bien de la noticia. Pobreza, que entra en escena acompañada por sus hijos Simplicidad y Sosiego, les comunica la buena nueva de que «el Príncipe soberano, hijo del eterno Padre, Dios de Dios y Señor nuestro», ha venido del cielo y se aposentará en su casa, conminándolos a ir a preparar su humilde posada. Riqueza pide ayuda a sus hijos, Solicitud y Curiosidad, para aderezar su majestuosa posada y éstos le ofrecen distintas galas y entretenimientos, entre ellos la actuación de dos truhanes, que entran en escena. Riqueza los acepta y se dirige a visitar a Pobreza. Ésta la recibe junto a sus hijos y responde a sus preguntas sobre la posible venida y la identidad del huésped que espera, argumentando a su hermana las razones por las que elegirá su morada. Riqueza, corrida, la abandona y se dirige a aguardar en su suntuoso aposento al mismo señor que ella. Pobreza exhorta a sus hijos a ver al Deseado y una cortina se abre y descubre el nacimiento. Ángeles y pastores lo acompañan, cantando y tocando intrumentos. Acabado el canto, se cierra la cortina y Pobreza y sus hijos se dirigen al nacimiento hasta que todo queda cubierto por dicha cortina.

GÉNERO: Auto alegórico celebrativo del nacimiento de Cristo para representar el día de Nochebuena. Su adscripción en el encabezamiento al género de «comedia» es aleatoria.

TEATRALIDAD: La tensión dramática entre los dos protagonistas, opuestos por naturaleza, no alcanza grandes cotas, pues es bastante suave. Galeas se muestra dueño de la puesta en escena, como revelan las acotaciones explícitas, a las que habría que sumar las marcas presentes al respecto en las acotaciones implícitas, que aquí omitimos, enumerando solo las primeras:

- En la Primera parte se introducen Mundo y Riqueza (fol. 110r).

- Segunda parte en que se introducen la Pobreza, y Simplicidad y Sosiego, sus hijos, y entran cantando (fol. 112v).

- Cantan los dos hermanos (fol. 113r).

- Cantan (fol. 116r).

- Cantan (fol. 116v).

- Tercera lición, en que se introducen Solicitud, y Curiosidad y Riqueza, y dos truhanes (fol. 116v).

- Entran los truhanes con la Solicitud, cantando con sonajas y guitarra (fol. 124r).

- Copla (fol. 124v).

- Cantan los truhanes (fol. 124v).

- Aquí les tañen a los truhanes y bailan un villancico (fol. 126r).

- Salen cantando los truhanes (fol. 126r). 
- Cuarta parte en que entra Pobreza con Sosiego y Simplicidad, sus hijos, cantando, y adelante entra la Riqueza (fol. 126v).

- Cantan los hijos de la Pobreza (fol. 129r).

- Cantan los hijos de la Pobreza (fol. 130r).

- Sale la Riqueza (fol. 131r).

- Aquí la Pobreza con sus dos hijos se hincan de rodillas y dicen cantando (fol. 131v).

- Aquí se abre una cortina y se descubre el nacimiento, donde está la Virgen Santisíma María, y nuestro bien, el niño Jesú desnudico, y el bienaventurado José, y ángeles y pastores con instrumentos diversos de música, y cantan los ángeles y los pastores con los instrumentos de música los tercetos siguientes (fol. 131v).

- Luego se torna a cerrar la cortina, y Pobreza y sus hijos, mientras se cantan los tercetos, se van recogiendo hacia el nacimiento de modo que todo queda cubierto debajo de la cortina (fol. 132r).

FINALIDAD: Propósito celebrativo y aleccionador, con motivo del nacimiento de Cristo.

VI

ENCABEZAMIENTO: Representación del nacimiento de Jesucristo Salvador nuestro (fols. 135r-165r), precedida por un INTROITO (fols. 132v-134v).

INTROITO: Introito para la comedia y represéntalo uno que suele representar un Simple. Muy gracioso: Pieza introductoria monologada de $80 \mathrm{vv}$. endecasílabos (agrupados en estrofas de cinco versos, con rima consonante en segundo y quinto: $A B C D B)$, recitado por «quien suele representar un Simple» ${ }^{64}$. Su estructura es la habitual en este tipo de introitos monologados: salutación laudatoria a los espectadores; captatio benevolentiae, mediante la justificación de la mezcla de lo «grave» y lo de «mediano regocijo» en la obra y la solicitud de dispensa por las faltas; presentación del argumento; y petición de atención. Las variantes entre este Introito y el que precede la homónima representación del MS. B2603 (New York, The Hispanic Society of America, fols. 25r-26r) son bastante escasas, observándose, en líneas generales, igual que ocurrirá en el cotejo de ambas representaciones, un mayor carácter cultista y una copia más cuidada en el Introito del ms. Galeas. Así,

a) La terminología y la información sumistrada en el encabezamiento del Introito es más precisa y más teatral en el ms. Galeas (Introito para la comedia y represéntalo uno que suele representar un Simple. Muy gracioso) que en el MS. B2603 (Yntroito. Represéntalo quien suele hazer un simple).

64. La métrica de este Introito coincide con la empleada en el Introito reseñado más arriba como pieza independiente. En la Sexta parte de la obra que prologa, hay también una serie de versos endecasílabos agrupados en cinco estrofas de cinco versos con rima consonante en segundo y quinto. 
b) En las grafías, el ms. Galeas mantiene grupos cultos latinizantes, que no conserva el MS. B2603: tractar / tratar, v. 12; conmigo / comigo, v. 18; signo / sino, v. 26; nescio / necio, v. 45; tractan / tratan, v. 50; divigno [hipercorrección] / divino, v. 50; sancto / santo, v. 56; sanctas / santas, v. 56; cognosçió / conosció, v. 67; cognoscido / conoscido, v. 68; demonstraçión / demostración, v. 72. También se aprecia algún caso de hipercorrección en el MS. B2603: rreçitasse / rrescitase [forma hipercorrecta], v. 16.

c) El MS. B2603 presenta casos de seseo (mesclarlas) y ceceo (liziados, perlezía, rriza), ausentes en el ms. Galeas (mezclarlas v. 13; y lisiados, v. 32, perlesía, v. 33 , risa, v. 35, respectivamente).

d) Por último, también encontramos variantes adiáforas: muy illustres / manificos (v. 1); querría / quería (v. 11); me a comido / me comió (v. 48); proveído / proveyendo, v. 59; seguía / siguía (v. 68), correspondiendo en estos casos la lección en primer término de cada una de las sucesivas parejas al ms. Galeas.

ENCABEZAMIENTO OBRA: Representación del nacimiento de Jesucristo Salvador nuestro. Es el argumento que el Hombre, ciego por el Pecado, fue guiado por la Ignorancia hasta la Ley y, conocido el Pecado, lo guió la Malicia hasta la Gracia, en la cual cobró la vista muerto el Pecado, y concluye con la demonstración del santo nacimiento en la vara de Jesé.

FIGURAS: Hombre, Pecado, Ignorancia, Profecía, Ley [divina], Malicia, Charlatán y Ley de gracia.

FORMA EXPRESIVA, EXTENSIÓN Y MÉTRICA: La obra está dividida en seis partes en prosa, con contrapuntos líricos (doce villancicos y un terceto, que arrojan un total de 40 versos cantados) y algunos parlamentos en verso en la Cuarta parte (siete tercetos encadenados) y Sexta parte (una octava real y cinco estrofas de versos endecasílabos con rima ABCDB). El Salmo 84,8, en lengua latina, cantado en la liturgia del primer domingo de Adviento, completa la parte lírica: «Ostende nobis, Domine, misericordiam tuam et salutare tuum da nobis» (fol. 164v).

La pieza está segmentada en seis partes, separadas por el vacío de personajes: PRIMERA PARTE en que se introducen el Hombre y el Pecado (fol. 135v).

SEGUNDA PARTE en que se introducen el Hombre y la Ignorancia y el Pecado, y viene ciego el Hombre (fol. 139r) ${ }^{65}$.

TERCERA PARTE en que se introducen la Profecía y la Ley (fol. 144v).

CUARTA PARTE en que se introducen el Hombre, Ignorancia y Pecado, Profecía y Ley [divina] (fol. 146r).

65. En el MS. B2603 a la derecha del término «siego» («y viene el honbre siego»), aparece la anotación «0jo», para llamar la atención sobre tres versos olvidados que se copian después, en el margen derecho del folio y un poco más abajo, y que hay que restituir a su lugar: tras esta acotación. Versos bien situados en el ms. Galeas. 
QUINTA PARTE en que se introducen el Hombre y Malicia y el Pecado y un Charlatán (fol. 151v).

SEXTA PARTE. Introdúcense el Hombre, Malicia, Pecado, Profecía, Ley de gracia, y al fin della se muestra el nacimiento en la vara de Jesé (fol. 158r).

ARGUMENTO: La pieza dramatiza el tema de la búsqueda por el Hombre caído de noticias acerca de su redención, que al fin llega con el nacimiento de Cristo. A lo largo de la misma, el Hombre se debate entre su esclavitud al Pecado y su deseo de apartarse de él, pues, aunque cegado por éste -hijo del Hombre y de la adúltera Inobediencia-, conserva parte de la clara lumbre de la Ley natural que Dios le imprimió en su creación. Guiado por Ignorancia, que con sus necedades pone una nota de comicidad en la pieza, busca incesantemente a Profecía para conocer la hora en la que llegará el remedio a su mal. Sin embargo, el Pecado lo distrae con continuos regocijos (un baile de villanos y serranicas y otro de momos) para que olvide su propósito. Profecía, que entra acompañada de su hermana la Ley divina, ratifica al Hombre la promesa de redención. Mientras llega el momento, la Ley divina le mostrará la causa de su mal para que se aparte de él. Conocido y rechazado el Pecado por el Hombre y abandonada la Ignorancia, la Ley divina se ofrece como su lazarillo hasta la llegada de la Ley de gracia con el nacimiento de Cristo, que le devolverá la vista y quebrará la cabeza al Pecado. No obstante, advierte al Hombre que, si ahora que conoce el Pecado lo sigue, en vez de Ignorancia lo servirá Malicia y será más culpable de sus actos. Y así sucede, pues el Hombre, sujeto otra vez al Pecado y guiado por Malicia en una escena situada en Sevilla, lamenta de nuevo su perdición y la de la ciudad hispalense, pintada por Malicia con muy vivos colores. Para distraerlo, el Pecado acude con un Charlatán, caracterizado como un lococuerdo que desenmascara a Malicia y vuelve a poner una nota de comicidad en la pieza. Ante una nueva petición de ayuda divina por el Hombre, acude la Profecía con la Ley de gracia, que anuncia su redención por el nacimiento de Cristo. Aunque la obra aparece salpicada por la comicidad en algunos pasajes, como hemos indicado, su tono es serio, respondiendo a lo que el prologuista en nombre del autor advierte en el Introito:

Señores muy ilustres, quien se emplea en dar reglas de aviso al avisado paréceme que hace lo que hace aquel que al claro sol añade lumbre o siembra en lo que ya está bien sembrado.

También el que en la hora de alegría en cosas muy sentidas pone mano lo mesmo es que querer mudar los tiempos: el otoño templado en el estío y en desabrido invierno el buen verano.

Por nuestro auctor lo digo, que querría tractar aquí esta noche cosas graves $y$ al fin se ha reducido de mezclarlas 
con otras de mediano regocijo,

que al buen gusto serán harto süaves (vv. 1-15).

Es decir, se trata de justificar la presencia de lo ridículo junto a lo grave, mezcla que se estima legítima para la ocasión, si bien de forma comedida, por respeto al lugar de representación y al cumplimiento de lo ordenado:

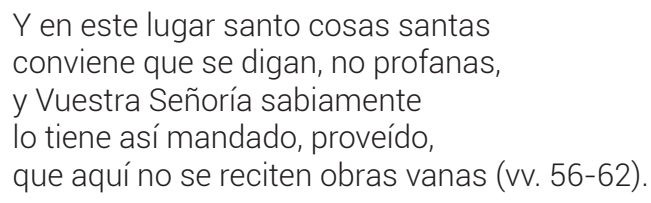

GÉNERO: Auto alegórico para festejar el nacimiento de Cristo, aunque en el Introito se le denomine comedia.

TEATRALIDAD: La tensión dramática reside en el personaje del Hombre, dividido entre su irrefrenable sujeción al Pecado y sus ansias de liberación de dicha esclavitud, si bien aminorada ante los espectadores al conocer desde el principio que el nacimiento de Cristo proporcionará final feliz a la pieza. Las acotaciones implícitas y explicitas muestran al dramaturgo dueño de la puesta en escena. Entre las explícitas, además de las reproducidas arriba para marcar la segmentación de la obra y la entrada de personajes en escena, aparecen estas tres:

- Aquí entran los villanos y serranicas y tañen y bailan y vanse con el Pecado (fol. 143v).

- Aquí entran los momos, bailando como matachines, y juegan al abejón y vanse, y luego entran cantando la Ley y la Profecía (fol. 148v).

- Aquí se descubre el santísimo nacimiento en la vara de Jesé, llena de reyes, patriarcas y profetas y en lo alto la Virgen Santísima María con el Niño Jesú Salvador Nuestro en los brazos, todos vivos, y entre tanto que está descubierto canta el Honbre con instrumentos este terceto (fol. 165r). La conversión del espacio de ficcón en espacio escénico en el caso de esta última acotación conllevaba una cierta complejidad escenográfica, tanto por el decorado requerido - «vara de Jesé»como por la utilización en él no de figuras de bulto o pintadas sino de carne y hueso $-«$ todos vivos»-.

FINALIDAD: Pieza de carácter doctrinal para celebrar el nacimiento de Cristo, con una sibilina crítica en boca de Malicia a la maldad que se encerraba en la ciudad de Sevilla (lugar donde se desarrolla la acción y reside el personaje), no solo entre la gente baja y de bajo entendimiento sino, en particular, entre «la gente de lustre, la prudente y avisada, y la rica», que «es la principal que me sigue», como precisa Malicia (fols. 153r-155r, las citas fol. 154v). No obstante, esta dura condena queda implícitamente anulada por la corrupta naturaleza del propio personaje que la realiza.

LA PIEZA EN EL MS. GALEAS Y EN EL MS. B2603: 
Igual que ocurría en el Inttroito de esta obra, el cotejo con su homónima del MS. B2603 arroja resultados semejantes: las variantes significativas son escasas, observándose, en líneas generales -como ya advertíamos-, un más acusado carácter cultista y una copia más cuidada en el caso del ms. Galeas. Así, se continúan mantiendo grupos cultos latinizantes, que no se conservan en el MS. B2603; no hay casos de seseo ni ceceo, frecuentes en el testimonio del MS. B2603; y, sobre todo, presenta mejores lecciones, en las que aquí no podemos detenernos, y dos adiciones: los términos «como matachines y juegan al auejón» (fol. 148v) que detallan más una acotación; y el verso «del Padre que es prinçipio sim prinçipio» (fol. 164r) que completan semántica y métricamente una estrofa, sin que por su falta en el MS. B2603 quede estragado el sentido. Frente a ellas, el ms. Galeas presenta la omisión de una frase del MS B2603 («y el ynsasiable amor que me tienes: tu grandeza», fol. 29v), cuya falta tampoco estraga el sentido en aquéll6. Como ya advirtieron Regueiro y Reichenberger, el testimonio del MS. 2603 es copia de otro, como muestran ciertos olvidos que se subsanan en la revisión de la misma ${ }^{67}$, pero las variantes con el ms. Galeas permiten aventurar que éste no fue su modelo ni Galeas copió de él68.

VII

ENCABEZAMIENTO: Dialogo de dos pastores, el uno llamado Silvano y el otro Alegría (fols. 173r-177v).

FIGURAS: Silencio (Silvano), pastor, y Alegría, pastora.

FORMA EXPRESIVA, EXTENSIÓN Y MÉTRICA: Verso y prosa. Comienza con empleo del verso: un villancico cantado (8A 8B 8B), seguido por una quintilla (8A 8B 8B 8A $8 \mathrm{~A})$, cinco estrofas de 6 versos, siendo el primero quebrado (4A 8A 8B 8B 8A 8B), un pareado (10A 8A), una quintilla (8A 8B 8B 8A 8B) y un pareado (4A 8A). A continuación, se pasa a la prosa, que está fragmentada por dos villancicos cantados y uno

66. He aquí ambos párráfos en uno y otro testimonio: Ms. Galeas: «Profheçía, hermana mía, graçiosamente as mostrado tu grandeza en dezir tanto en tam poco y el amor en la alegría con que lo das a entender, y con muy grande razón, pues sabes que soy venida para cumplir tu palabra (fol. 145r) / MS B2603: «Profecía, hermana mía, graciosamente as mostrado tu grandeza y el ynsasiable amor que me tienes: tu grandeza en dezir tanto en tan po[co] y el amor en el alegría con que lo das a entender, y con muy grande razón, pues sabes que soy venida para cunplir tu palabra» (fol. 29v).

67. En el fol. 28r, a la derecha del término «siego» figura la marca «ojo», para llamar la atención sobre tres versos olvidados que se copian después en el margen derecho del folio y un poco más abajo, y que deben restituirse a su lugar, como ya se ha indicado; y en el fol. 29v, el término Villancico y los tres versos que lo siguen, separados por rayas inclinadas, están escritos, en una sola línea, entre la última de esta Segunda parte y las rayas de separación que marcan el final de ella y el comienzo de la Tercera, con letra más pequeña, advirtiéndose que se trata de un añadido tras un olvido.

68.Para los citados estudiosos, «Therefore, the Galeas MS cannot be a copy of the anonymus MS, but both, independently, must be based on a third unknown MS. (Regueiro y Reichenberger, 1984, vol. I, p. 224). Límites de espacio impiden desarrollar en este artículo un cotejo más preciso entre ambos manuscritos, que se incluirá en la edición del texto de Galeas. 
tercero de cierre del auto, siempre con el mismo esquema (8A 8B 8B). En conjunto, un total de 56 versos y 135 líneas en prosa aproximadamente.

ARGUMENTO: El pastor Silencio (Silvano en el título y en las dos primeras adscripciones del parlamento), excediendo su propia naturaleza, rompe a cantar y hablar para publicar las excelencias de la venida de Dios al mundo en ese día. Su hermana Alegría, extrañada, le pregunta la causa por la que ha mudado su condición, argumentándole Silencio que es para proclamar la venida del Deseado. Alegría, regocijada, le pide que le indique cuándo y dónde nació este divino Señor. Silencio le explica que hoy es el día de su natividad y le detalla cómo y dónde fue. Alegría expresa su deseo de ir a ver al recién nacido y Silencio la lleva, entonando ambos una canción.

GÉNERO: Coloquio alegórico sobre el nacimiento de Cristo, con numerosas referencias bíblicas.

TEATRALIDAD: Como se indica en su encabezamiento es un diálogo entre dos pastores alegóricos sin rasgos de rusticidad, desprovisto de tensión dramática y con una sola acotación explicita - «Y luego proseguía el mismo Silvano representando lo que se sigue» (fol. 173r), que, unida a las implícitas, muestra al autor como dueño de la puesta en escena.

FINALIDAD: Pieza de tema y personajes alegóricos, de carácter doctrinal, para celebrar el nacimiento de Cristo el día de su natividad.

Terminado este acercamiento a las piezas, nos preguntamos cuál sería su ámbito de escritura y de representación. La profesión religiosa de Galeas a los 23 años, tras uno de noviciado, induce a pensar que quizá no las escribió antes de su entrada en el monasterio, siendo tal vez más probable que compusiera su producción poética y dramática en la soledad de su celda, pues entre las ocupaciones de los cartujos se encontraba la escritura ${ }^{69}$. El ámbito de representación, nos parece en cambio más amplio. Parte de ella podría haberse representado -o leído- entre los muros conventuales, dirigida a sus correligionarios, pero la Representación breve para el día del Santísimo Sacramento... no estaba compuesta para intramuros $-y$ represéntase al pasar del Santísimo Sacramento por alguna calle..., indica su encabezamiento-, así como tampoco la Representación del nacimiento de Jesucristo Salvador nuestro..., que en 2005, donde la daba a conocer por primera vez como anónima, la situaba -junto con las otras dos de esa reducida colección- en el contexto de la catedral hispalense, sin que por ahora podamos aportar nuevos datos al respecto. Y un tercer caso podría ofrecerlo el Introito para representación a la

69. Historiando esta actividad escritora de los cartujos, el R. P. General de la O. de la C., Fr. Fernando, escribía en 1960: «Nuestros escritores ordenan el fruto de sus investigaciones o de su meditación afectiva en comentarios o en tratados teológicos o ascéticos, escritos, muchas veces, no con miras a una publicación ulterior, sino tan solo para la propia edificación del autor o de sus hermanos de hábito...» (Gómez, 1970, p. 8). 
venida del Ilustrísimo Arzobispo de Sevilla después de mucha absencia de prelado en ella, pieza laudatoria de circunstancias.

Por último, después de esta presentación de las obras, se impone proyectarlas sobre un marco más amplio: el del corpus teatral castellano del siglo XVI y principios del XVII. Para ello, me serviré de las consideraciones que hacía en 2005 sobre las tres piezas que entonces estudiaba (MS. B2603), la segunda de las cuales era con variantes la penúltima de las aquí descritas, como se ha indicado. A diferencia de lo que ocurre con obras compuestas para la Navidad por Juan del Encina, Lucas Fernández, Gil Vicente, Bartolomé de Torres Naharro, Pero López Ranjel, Fernán López de Yanguas, Pedro Suárez de Robles o Diego Sánchez de Badajoz, las cuatro de Galeas que celebran el nacimiento de Cristo no se insertan en la tradición del teatro de pastores, tan unido a esta festividad litúrgica, sino en la dramatización de un mundo alegórico, tanto por sus personajes como por los temas que escenifican. Entre los dramaturgos citados, ya el portugués Gil Vicente había ofrecido ejemplo de ello y, en particular, el extremeño Diego Sánchez de Badajoz, cuya Recopilación en metro se publica en Sevilla, en 1554, por el clérigo Juan de Figueroa, su sobrino. Sin embargo, en ambos autores, el vehículo expresivo es el verso, mientras que en tres de las cuatro piezas natalicias de Galeas es predominantemente la prosa.

Este empleo de la prosa, así como otras características de nuestras obras, conducen a conectarlas con la línea en que se insertan las tres piezas del MS. B2603 y más atrás en el tiempo en la tradición de la producción de Lope de Rueda o de Alonso de la Vega, autores-actores que, junto a otros como Juan Timoneda, están experimentando a mediados del siglo XVI una nueva forma de hacer teatro, en la que, a imitación de los modelos italianos, la prosa sustituye al verso. Como señala Alfredo Hermenegildo, a propósito de esta novedad en el teatro de Lope de Rueda, «el uso de la prosa permite llegar más fácilmente a crear texto en el momento mismo de la representación» y le da al teatro «una movilidad y flexibilidad que el verso, muy útil por otra parte, le niega» ${ }^{70}$. Además, añadiríamos nosotros, la naturalidad de la prosa frente al mayor artificio del verso proporcionaba una forma más fácil de escritura -y de recitación- para autores circunstanciales o aficionados, como pudo ser Galeas. Ni el sevillano Lope de Rueda, ni Alonso de la Vega, «vecino de Sevilla» en 1560, le serían ajenos. A Lope de Rueda no solo lo encontramos en relación con las representaciones del Corpus hispalense en una escritura de 1543 y en 1559, sino que en 1564 bautiza en Sevilla a su hija Juana Luisa y en su testamento, a través del reconocimiento de una deuda, deja atestiguada la representación de una farsa durante doce días en casa del ya citado Juan de Figueroa, presbítero, vecino de Sevilla y un activo hombre de teatro en los años centrales del siglo XVI (participa con carros de representación en el Corpus de 1559, 1560, 1561 y 1562) 71 . Y, a su vez, Alonso de la Vega, que fue miembro de la compañía de Rueda, también participará en la festividad del Corpus, con dos carros de representación y siete danzas en $1560^{72}$. Por otra parte, la producción dramática de Lope de Rueda y Alonso de la Vega aparece publicada por Juan

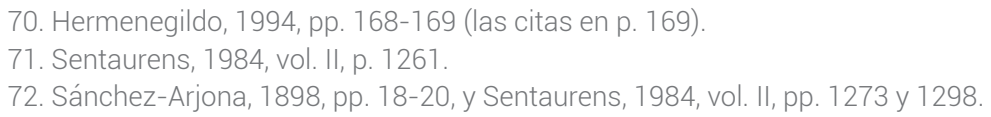


Timoneda, en Valencia, en la década de 1560: en 1566 ven la luz las Tres famosíssimas comedias de Alonso de la Vega y, en 1567, Las quatro comedias y dos coloquios pastoriles y El Deleytoso de Lope de Rueda, con una segunda edición de la primera de estas dos últimas obras en Sevilla, por Alonso de la Barrera, en 1576. Es verdad que, dada la fecha de nacimiento de Galeas, 1567, ese influjo no pudo ser directo, es decir, en vida de estos actores-autores, pero si pudieron marcarle las huellas que dejaron; esas otras tres representaciones del nacimiento aludidas (MS. B2603) -la segunda muy plausiblemente suya, pues, al menos, bajo su autoría aparece en el manuscrito que exhumamos (MS. HC380/611)-; las representaciones de las compañías de commedia dell'arte que visitan Sevilla desde el último tercio del siglo (la célebre de Ganassa llega por primera vez en 1575), así como la actividad dramática que hubo en los colegios de la Compañía de Jesús, las universidades y las academias en la capital hispalense durante la segunda mitad del Quinientos.

La escritura teatral en prosa de esos años del Quinientos, que podríamos situar en un arco comprendido entre las décadas de 1540 y 1570 y más adelante, como se observa, además de en lo hasta ahora referido, en el Auto de los desposorios de Moysén y el Auto de Naval y de Abigaíl del Códice de Autos Viejos -que se han atribuido a Lope de Rueda- ${ }^{73}$, será, con algunas excepciones como las citadas de Galeas, superada a medida que avanza el siglo por la primacía del verso, que acabará imponiéndose a pesar de la ardiente defensa que hacen de aquélla los comediantes italianos que actuaron en España en el último tercio del siglo XVI ${ }^{74}$. Uso éste del verso al que no se sustraen por completo los autores de algunas de las obras en prosa citadas, como tampoco el propio Galeas que, en cuatro de las siete composiciones presentadas, lo emplea como único vehículo expresivo: Representación breve para el día del Santísimo Sacramento...; Introito para representación a la venida del Ilustrísimo Arzobispo de Sevilla...; Para la festividad del nacimiento de Nuestro Salvador y paces fechas en la discordia entre Fortaleza y Flaqueza; y La historia de cuando Abraham echó de casa a Ismael y Agar, su madre.

En la Representación del nacimiento de Jesucristo Salvador nuestro, además de en el Introito, el endecasílabo se emplea en algunos pasajes de la Cuarta y Sexta partes, agrupados en siete tercetos encadenados (Cuarta parte) y una octava real y cinco estrofas de cinco versos: ABCAB (Sexta parte), como se ha indicado. La presencia de este metro italiano en el teatro anterior a Lope de Vega se halla documentada por Morley, con un uso tímido del soneto y la octava en una o dos piezas representadas en el período de 1530 a 1575, relegando el uso del terceto al período comprendido entre 1575 y $1587^{75}$. Es verdad que el citado investigador establece su cronología a partir de una serie de obras entre las que no aparecen las nuestras, pero el panorama métrico que traza puede servir de punto de referencia para la ubicación de las que estudiamos. Con estas reservas, la mezcla de prosa

73. Ver Reyes Peña, 1988, t. I, pp. 155-164.

74. Sobre el uso y defensa de la prosa por la generación de autores-actores y por los comediantes italianos, su abandono posterior y el triunfo definitivo del verso, ver Ojeda Calvo, 1995, pp. 129-130, Froldi, 1996, pp. 278-289, y Granja, 1998, pp. 257-262.

75. Morley, 1925, pp. 527-529.

HIPOGRIFO, 5.1, 2017 (pp. 115-154) 
y versos endecasílabos en esta pieza permite mantener esa datación del último cuarto del Quinientos o principios del Seiscientos. ¿Sería esa utilización del verso por Galeas -nos preguntamos - un deseo de romper la exclusividad de la prosa? Pero conviene tener en cuenta que el uso del verso había continuado vigente en el teatro religioso -basta considerar las piezas del Códice de Autos Viejos-, si bien con un predominio de los metros españoles, y él mismo lo utiliza con exclusividad en cuatro de sus siete composiciones ¿O respondería más bien a un deseo de dignificar con el prestigio de los metros italianos la forma expresiva de algunos personajes o de determinados pasajes? ${ }^{76}$ Sin embargo, su empleo en el Introito de esta representación, ejecutado por «quien suele hacer un Simple», aunque en tono serio, resta fuerza a esta suposición, al menos que, en el caso de los dos Introitos, su uso viniera determinado por la categoría de la persona a la que van dirigidos.

Limitaciones de espacio aconsejan terminar nuestro estudio, no sin antes advertir que el deseo de presentar las siete obras individualmente y en su conjunto ha determinado ciertas generalizaciones en menoscabo de precisiones y detalles, que aparecerán en la edición de las piezas. Nuestra intención ha sido arrojar más luz en la biografia de Francisco Galeas y dar a conocer su obra dramática, incorporándola a la historia del teatro castellano de la época.

\section{BIBLIOGRAFÍA}

Álvarez Márquez, M. ${ }^{a}$ del Carmen, «Manuscritos localizados pertenecientes en otro tiempo al monasterio cartujo de Santa María de las Cuevas, extramuros de la ciudad de Sevilla», Scriptorium, 52, 2, 1998, pp. 388-408.

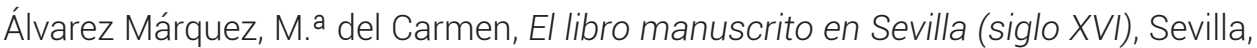
Ayuntamiento de Sevilla, 2000.

Álvarez Márquez, M. ${ }^{a}$ del Carmen, «El Monasterio de Santa María de las Cuevas», en Fondos y procedencias. Bibliotecas en la Biblioteca de la Universidad de Sevilla. Exposición Virtual 2013, coord. Eduardo Peñalver, Sevilla, Universidad de Sevilla, 2013, pp. 179-187. Disponible en línea: <http://expobus.us.es/fondos> [8/2/2016].

Álvarez Márquez, M. ${ }^{\text {a }}$ del Carmen, Bibliotecas privadas de Sevilla en los inicios de la Edad Moderna, Zaragoza, Libros Pórtico, 2014.

Archivo biográfico de España, Portugal e Iberoamérica, ABEPI, I, dir. y redac. Víctor Herrero Mediavilla y Lolita Rosa Aguayo, München [etc.], K.G. Saur, 1986; ABEPI, II, ed. Víctor Herrero Mediavilla, München [etc.], K.G. Saur, 1991-1993; ABEPI, III, ed. Víctor Herrero Mediavilla, München [etc.], K.G. Saur, 1996-1998, ed. en microficha.

76. En la Representación del nacimiento de Jesucristo Salvador nuestro, aparecen en el cuerpo de la obra en un diálogo entre el Hombre y Ley divina (siete tercetos encadenados), en un parlamento en el que el Hombre se dirige a Dios (una octava) y en el pasaje final cuando Ley de gracia comunica al Hombre el nacimiento de Cristo (cinco estrofas de cinco versos). 
Aut. = Diccionario de Autoridades, Madrid, Real Academia Española, 1726-1739. Ed. facs.: Madrid, Gredos, 1984.

Bassegada i Hugas, Bonaventura, «Introducción», en Francisco Pacheco, Arte de la

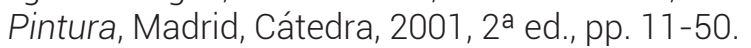

Ceán Bermúdez, Juan Agustín, Diccionario histórico de los más ilustres profesores de las Bellas Artes en España (1800), Madrid, Akal, 2001, ed. facs.

Collantes de Terán, Francisco, «Galería de retratos de sevillanos ilustres que se conserva en la Biblioteca del Excmo. e Ilmo. Cabildo...», Archivo Hispalense, 3, 1887, pp. 169-176 y 234-241.

Cuartero y Huerta, Baltasar, Historia de la Cartuja de Santa María de las Cuevas, de Sevilla, y de su filial de Cazalla de la Sierra, Madrid, Turner, 1988, 2 tomos.

Cuartero y Huerta, Baltasar, Historia de la Cartuja de Santa María de las Cuevas, de Sevilla, y de su filial de Cazalla de la Sierra. Apéndices documentales, introd. Antonio Domínguez Ortiz, Cádiz, Consejería de Cultura y Medio Ambiente y la Real Academia de la Historia en conmemoración del V Centenario, Junta de Andalucía, 1991.

Diccionario histórico de las calles de Sevilla, dir. Antonio Collantes de Terán Sánchez, Josefina Cruz Villalón, Rogelio Reyes Cano y Salvador Rodríguez Becerra, Sevilla, Consejería de Obras Públicas y Transportes-Excmo. Ayuntamiento de Sevilla, 1993, 3 vols.

Flecniakoska, Jean-Louis, La loa, Madrid, SGEL, 1975.

Froldi, Rinaldo, «l comici italiani in Spagna», en Covegno di Studi «Origini della Commedia Improvvisa o dell'Arte. Roma, ed. Myriam Chiabò y Federico Doglio, Roma, Centro Studi sul Teatro Medioevale e Rinascimentale, 1996, pp. 273289.

Gómez, Ildefonso M., en colaboración con un cartujo del Aula Dei, Escritores cartujanos españoles, Barcelona, Abadía de Montserrat, 1970 (volumen separata de Studia Monastica, 9, 1967-11, 1969, con algunas correcciones de detalle, un nuevo prólogo del P. General de la Cartuja y cinco índices).

Granja, Agustín de la, «La fecha de composición de El retablo de las maravillas», Anales Cervantinos, 34, 1998, pp. 255-267.

Hermenegildo, Alfredo, El teatro del siglo XVI, Madrid, Júcar, 1994.

Méndez Bejarano, Mario, Diccionario de escritores, maestros y oradores naturales de Sevilla y su actual provincia: contiene este volumen 3.830 notas bio-bibliográficas (1922-1925), Sevilla, Padilla, 1989, ed. facs.

Morley, S. Griswold, «Strophes in the Spanish Drama before Lope de Vega», en Homenaje ofrecido a Menéndez Pidal, Madrid, 1925, vol. I, pp. 505-531. 
Ojeda Calvo, María del Valle, «Nuevas aportaciones al estudio de la Commedia dell'arte en España: el zibaldone de Stefanello Bottarga», Criticón, 63, 1995, pp. 119-138.

Ollero Pina, José Antonio, La Universidad de Sevilla en los siglos XVI y XVII, Sevilla, Universidad de Sevilla-FOCUS, 1993.

Pacheco, Francisco, Arte de la pintura, ed. Bonaventura Bassegoda i Hugas, Madrid, Cátedra, 2001, 2. ${ }^{\text {e ed. }}$

Palomino de Castro y Velasco, Antonio, «El R. P. D. Francisco Galeas, monje cartusiano, pintor», en El Parnaso español pintoresco laureado. Tomo tercero. Con las vidas de los pintores y estatuarios eminentes españoles, que con sus heroicas obras han ilustrado la nación. Y de aquellos estranjeros ilustres que han concurrido en estas provincias, y las han enriquecido con sus eminentes obras; graduados según la serie de el tiempo, en que cada uno floreció [...] (En Madrid. Año de 1724), en El museo pictórico y escala óptica: Tomo segundo ..., Madrid, por la Viuda de Juan García Infanzón, 1724, pp. 279-280.

Regueiro, José M. ${ }^{a}$ y Arnold G. Reichenberger, Spanish Drama of the Golden Age. A Catalogue of the Manuscript Collection at the Hispanic Society of America, New York, The Hispanic Society of America, 1984, 2 vols.

Reyes Peña, Mercedes de los, El «Códice de Autos Viejos». Un estudio de historia literaria, Sevilla, Alfar, 1988, 3 vols.

Reyes Peña, Mercedes de los, «Tres representaciones inéditas del siglo XVI sobre el nacimiento de Cristo», en «Por discreto y por amigo». Mélanges offerts à Jean Canavaggio, ed. Christophe Couderc y Benoît Pellistrandi, Madrid, Casa de Velázquez, 2005, pp. 319-343.

Rincón, José María, Protocolo / de el Monasterio de Nra. S. a / Santa María de las Cuevas. / Tomo Primero / Anales en los Tres Primeros Siglos / de su Fundacion. / [...] / Van Insertos los de la Santa Cartuxa de la Purisima Concepcion de Cazalla Fundada y Dotada por esta de las Cuevas / [... ] / Año de 1744 / con colofón de 1745.

Rodríguez-Moñino, Antonio y María Brey Mariño, Catálogo de los manuscritos poéticos castellanos existentes en la biblioteca de The Hispanic Society of America (siglos XV, XVI, XVII), New York, Hispanic Society of América, 1965.

Rouanet, Léo (ed.), Colección de autos, farsas y coloquios del siglo XVI, BarcelonaMadrid-Mâcon, Protat Hermanos Impresores, 1901, 4 vols. Ed. facs.: Hildesheim-New York, Georg Olms Verlag, 1979.

Ros, Carlos, Los Arzobispos de Sevilla. Luces y sombras en la sede hispalense, Granada, ANEL, 1986.

Sánchez-Arjona, José, El teatro en Sevilla en los siglos XVI y XVII (Estudios históricos), Madrid, Establecimiento Tipográfico de A. Alonso, 1887. Ed. facs.: Sevilla, Centro Andaluz de Teatro-Padilla Libros, 1990. 
Sánchez-Arjona, José, Noticias referentes a los anales del teatro en Sevilla desde Lope de Rueda hasta fines del siglo XVII, Sevilla, Imp. de E. Rasco, 1898. Ed. facs.: Sevilla, Ayuntamiento, 1994, con prólogo y apéndice bibliográfico de Piedad Bolaños Donoso y Mercedes de los Reyes Peña.

Sánchez Gordillo, Alonso, Svmaria relación del insigne Monasterio de Santa María de las Cuevas de Sevilla, del Orden de la Cartvxa. Ordenda por el Licenciado Alonso Sánchez Gordillo, Presuítero, natural de Seuilla, Protonotario Apostólico, Abad mayor de la Clerecía, Fiscal de la Reuerenda Cámara en todo el Arzobispado. Beneficiado propio y cura de la Iglesia de la Magdalena. Juez apostólico en muchas causas eclesiásticas. En este año de 1663, de su hedad 72, en Abad Alonso Sánchez Gordillo, Memorial sumario de los arzobispos de Sevilla y otras obras, ed. José Sánchez Herrero, Prólogo de Juan Gil e Índices de Silvia María Pérez González, Sevilla, Ayuntamiento de Sevilla, 2003, pp. 338-394.

Sentaurens, Jean, Séville et le théâtre de la fin du Moyen Âge à la fin du XVIIe siècle, Bordeaux, Presses Universitaires, 1984, 2 vols.

\section{APÉNDICE}

La historia de cuando Abraham echó de casa a Ismael y Agar, su madre ${ }^{77}$

$\begin{array}{ll}\begin{array}{ll}\text { ISMAEL } & \text { ¡Hola Isaac, Isaac hermano! } \\ \text { ISAAC } & \text { Ismael, ¿qué es lo que quieres? } \\ \text { ISMAEL } & \text { Que no se nos pase en vano } \\ & \text { el tiempo que en los placeres } \\ & \text { podemos meter la mano. } \\ \text { ISAAC } & \text { ¿En placer qué tiempo es } \\ & \text { el que se puede gastar? } \\ \text { ISMAEL }{ }^{78} & \text { El tiempo de la niñez. } \\ \text { ISAAC } & \text { Para bien se acostumbrar, } \\ & \text { debe ser muy al revés. } \\ \text { ISMAEL } & \text { iValme Dios qué hipocresía! } \\ & \text { Ahora en la tierna edad } \\ \text { iSAAC } & \text { No huieres huir alegría? } \\ & \text { que ella holgarse querría. } \\ \text { De mi propria inclinación, }\end{array} \\ & \end{array}$


por do caminas camino,

mas la ley de la razón,

ajustada a lo divino,

me dice que es sinrazón.

ISMAEL De hombres muy avisados

han oído mis oídos

que los niños muy templados

a edad madura venidos

los vicios tienen doblados,

que lo que por una vía

les falta en la juventud

por experiencia se vía

que, llegada senectud,

en mil maneras crecía.

$Y$ así, yo quiero holgarme

en este tiempo presente,

que después puedo enmendarme.

ISAAC Yo no, que es inconveniente

para bien acostumbrarme,

que en la niñez aprendida

cualquiera mala costumbre

queda en los huesos metida,

de donde sin pesadumbre

no puede ser despedida;

$y$, si en tierno corazón

virtud temprano se encierra,

llegado a su perfección

muy menor será la guerra

de su mala inclinación.

ISMAEL Pues hoy habéis de jugar conmigo a los repelones.

ISAC

No pienso agora burlar.

ISMAEL

Con estos dos torniscones ${ }^{79}$, podréis el juego dejar.

SARRA Ismael, ¿qué te parece? ¿A Isaac me tratas así? ¿Aquese pago merece la que por tu madre y ti tales congojas padece.

No llores, mi hijo amado,

que Ismael me pagará

lo que a ti te ha enojado.

79. v. 49 torniscones: «golpe que se da en la cara con el revés de la mano», S. v. torniscón (Aut.). 
ISAC

ABRAHAM

SARRA

ABRAHAM
Señora, el pagar será

perdonarle lo que ha errado.

Sarra, mi mujer amada, ¿qué has?, ¿qué quieres de mí, que siento que estás penada?

Estoy quejosa de ti, y de tu esclava, afrentada. Señor, respóndeme agora a esta hazaña brava de que el alma sangre llora: yo, señora, soy la esclava y Agar, la esclava, señora.

Si te la di por mujer y ella conmigo estropieza, declara si ella ha de ser la que mande y la cabeza, y yo la que he de obedecer. Agar, como mi enemiga, ni me ama ni obedece. Su hijo al niño castiga y no hay cosa que se ofrece en que no me contradiga.

Si aquesto tú lo consientes, por ti pasaré por ello,

mas, si lo contrario sientes, a ti toca el proveello y quitar inconvenientes.

\section{SEGUNDA PARTE}

No permita el Hacedor que yo quiera desconcierto, que sería grande error y dar un camino abierto para turbar nuestro amor.

Si yo amor a Agar mostraba, a ti con grande mejora, y en Agar, como en la esclava y no como a la señora ${ }^{80}$, porque en ti subió la fee

80. v. 94 Verso añadido de otra mano y tinta para subsanar un olvido en la copia, como ya se ha indicado. Ésta es la impresión, aunque los rasgos son muy parecidos. La quintilla, al fartarle un verso, se convierte en redondilla, con sentido completo. De aquí, que no se haya puesto línea de puntos para conseguir en el cómputo versal dicha quintilla, si es que primitivamente lo era. 
que de lo que a Agar amé amor me pidió a mí celos, si en algo a tu amor falté. Y como de mí entendí, que su amor no me cegó, cuando más amor le di entiende que no llegó a lo menos que amo a ti. $Y$ pues que tanto se aleja la que es sierva de la esposa, tu pasión, mi Sarra, deja, que parece baja cosa formar de tu esclava queja.

SARRA

Abrahan, este favor que me haces lo agradezco, mas, si es paga del amor, el amor bien lo merezco, aunque en ti fuera mayor, que mi amor es verdadero y de punto más subido, porque es un amor entero y tu amor amor partido y, por tanto, más grosero; que, aunque más ames a mí, al fin amas a tu Agar y es imposible que en ti pueda firme amor estar no empleado todo en mí. $Y$, puesto que lo que digo es para mí dura cosa, el Señor es buen testigo que desto no estoy quejosa, pues yo la casé contigo. Lo que tengo que quejarme y pedir a Dios paciencia es ver que la que ha de honrarme con tan grande inobediencia se atreva a menospreciarme. Y porque aquesta doncella no llegue a hacerse brasa para que me abrase en ella, a tu Agar echa de casa y a Ismael también con ella. Con esto paz se conserva y así será lo primero, y entienda Agar, la proterva, 


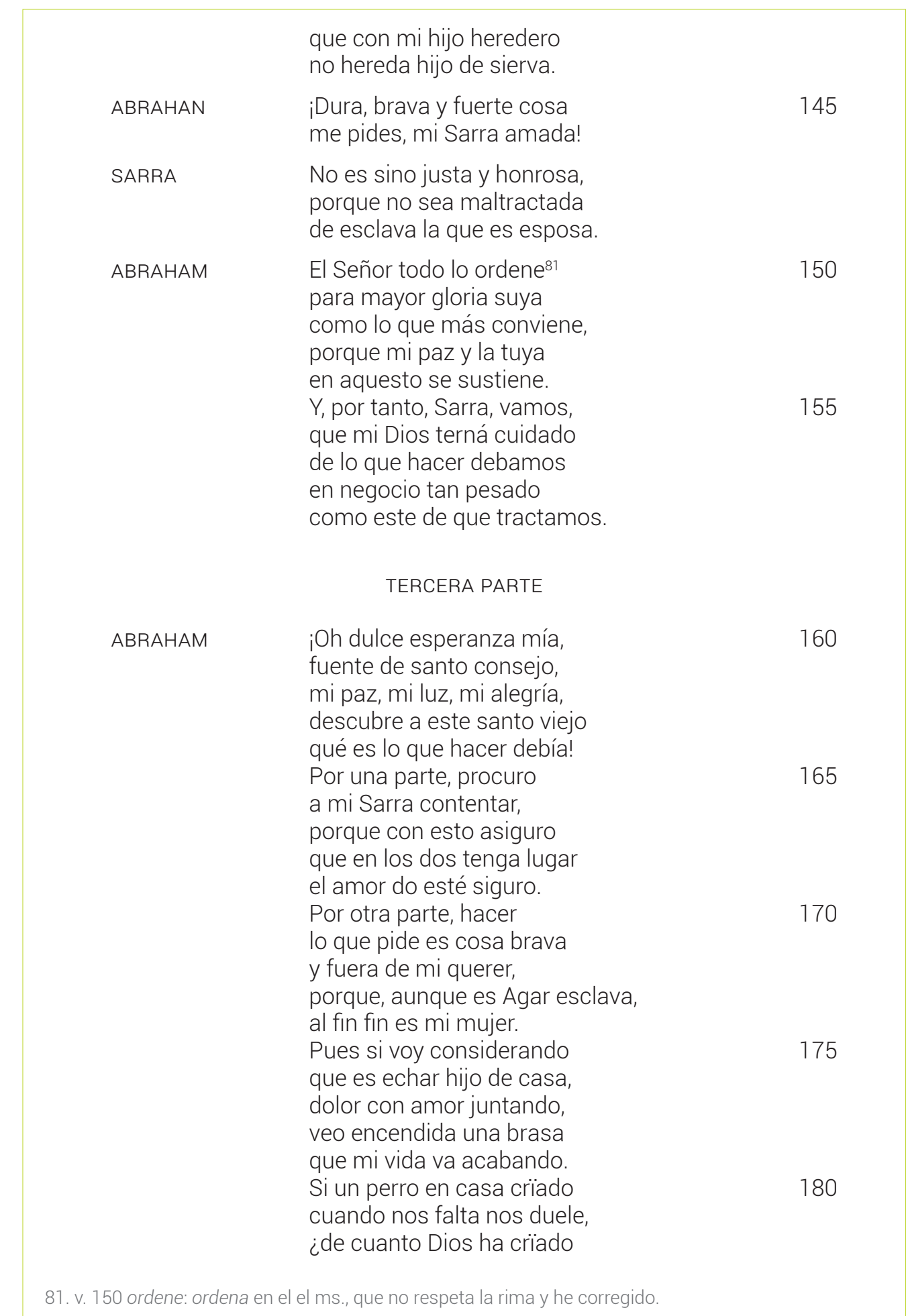




\begin{tabular}{|c|c|c|}
\hline & $\begin{array}{l}\text { qué cosa habrá que consuele } \\
\text { la falta de un hijo amado? }\end{array}$ & \\
\hline ÁNGEL & $\begin{array}{l}\text { Si pena, Abraham, te hiere, } \\
\text { con cordura la despide } \\
\text { y, si mucho te doliere } \\
\text { hacer lo que Sarra pide, } \\
\text { entiende que Dios lo quiere. } \\
\text { No vivas vida penosa, } \\
\text { huyendo de regocijo, } \\
\text { ni tengas por dura cosa } \\
\text { echar de casa a tu hijo } \\
\text { y con él a Agar tu esposa, } \\
\text { que la promesa sin par } \\
\text { que a tu sucesión se dio } \\
\text { en solo Isac ha lugar, } \\
\text { no en Ismael que nació } \\
\text { de esclava captiva, Agar. } \\
\text { No penes por Ismael } \\
\text { ni por el aumento suyo, } \\
\text { que, aunque tú te olvides dél, } \\
\text { por solo ser hijo tuyo } \\
\text { tiene Dios cuenta con él. }\end{array}$ & 185 \\
\hline ABRAHAM & $\begin{array}{l}\text { Si así lo quiere el Señor, } \\
\text { cúmplase en mí su mandado, } \\
\text { mas, jay!, que do hay amor } \\
\text { es cierto, absente el amado, } \\
\text { el dolor del amador. }\end{array}$ & 205 \\
\hline ÁNGEL & $\begin{array}{l}\text { Bien sé que te llegará } \\
\text { el dolor a las entrañas, } \\
\text { más advierte que será } \\
\text { padre de grandes compañas } \\
\text { que Dios por ti le dará. } \\
\text { Y mira con sentimiento } \\
\text { que, pues Dios así lo ordena, } \\
\text { no es sin grande fundamento, } \\
\text { por tanto, acorta tu pena } \\
\text { y alarga tu sufrimiento. } \\
\text { ¡Quédate con el Señor, } \\
\text { que vuelvo al que me envió! }\end{array}$ & 210 \\
\hline ABRAHAM & $\begin{array}{l}\text { ¡Bendito sea su amor, } \\
\text { que con dulzura templó } \\
\text { el agro }{ }^{82} \text { de mi dolor! }\end{array}$ & \\
\hline
\end{tabular}

